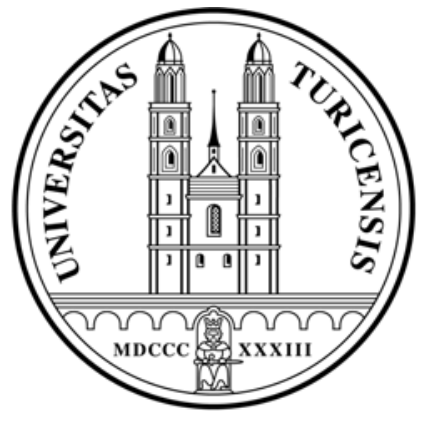

Institute for Empirical Research in Economics

University of Zurich

Working Paper Series

ISSN 1424-0459

Working Paper No. 425

In the Eye of the Beholder: Subjective Inequality Measures and the Demand for Redistribution

Andreas Kuhn

August 2009 


\title{
In the Eye of the Beholder: Subjective Inequality Measures and the Demand for Redistribution
}

\author{
Andreas Kuhn, University of Zurich and IZA*
}

August 2009

\begin{abstract}
This paper presents a simple conceptual framework intended for describing individuals' subjective evaluations of occupational wage inequality and their demand for redistribution. Most importantly, the framework explicitly allows for the distinction between individuals' perceptions and their normative beliefs. I illustrate the framework using Swiss survey data from the International Social Survey Program. While most individuals accept quite large wage differentials across occupations, they also prefer a lower level of overall wage inequality than what they perceive to exist. Consistent with previous evidence, the empirical analysis also shows that financial self-interest, social norms about distributive justice and perceptions of how wages are determined in reality all simultaneously influence the demand for redistribution. Finally, I show that subjective inequality measures and the demand for redistribution are substantially significant predictors of both individuals' support for government intervention and their party identification. This result provides indirect evidence on the presumed link between perceptions and beliefs on the one hand and and political outcomes on the other hand.
\end{abstract}

JEL classification: D3, D63, H1

Keywords: Subjective inequality measures, demand for redistribution, distributive justice, party identification, support for the welfare state

\footnotetext{
* Josef Falkinger, Michael Kosfeld, Rafael Lalive, Manuel Oechslin, Jan van Ours, Oliver Ruf, Rainer Winkelmann, Michael Wolf, Josef Zweimüller, seminar participants in Bonn and Zurich and participants of the 8th IZA European Summer School in Labor Economics in Buch/Ammersee provided many helpful comments and suggestions. I also thank Christian Bächle, Volker Bornschier, Mark Herkenrath, and Stéphanie Zeier for helpful comments on an earlier draft of this paper. Financial support by the Research Fund of the University of Zurich (grant number 53211602) and by the Austrian Science Fund (National Research Network: "The Austrian Center for Labor Economics and the Analysis of the Welfare State") is gratefully acknowledged. Contact: Institute for Empirical Research in Economics, University of Zurich, Mühlebachstrasse 86, 8008 Zurich, Switzerland; kuhn@iew.uzh.ch.
} 


\section{Introduction}

Redistribution is one of the primary objectives of the modern welfare state. Such redistributive interventions are most often justified on the grounds that redistribution ensures certain minimum standards of living and insures individuals against unexpected loss of income following, for example, job loss or sickness. However, redistributive measures are often also explicitly aiming at the reduction of existing inequalities per se (Barr, 1992). It is therefore no surprise that all OECD countries spend huge amounts of resources on redistribution. In the mid-2000s, for example, public cash benefits accounted for 15.8 percent of disposable household income of all individuals in working age and the tax burden ammounted to 31.1 percent for the same group of individuals, on average over all member countries of the OECD (OECD, 2008). In fact, overall expenditure on redistribution is arguably even higher than these figures suggest because public goods are also financed by taxes they often have an implicit redistributive flavor. Therefore, the question arises of why so much redistribution takes place in the first place.

Most economists probably tend to think that the amount redistribution is, at least in part, determined by voting and thus shaped by individuals' preferences over redistribution (Borck, 2007). ${ }^{1}$ In fact, inspired by the well-documented differences in the distribution of earnings and the differences in the impact of redistributive measures across countries (for recent empirical evidence, see OECD (2008)), recent theoretical work has pushed forward the idea that the amount of redistribution is essentially linked to individuals' beliefs about distributive justice as well as their perceptions of the determinants of inequality. Indeed, as pointed out by Bénabou and Tirole (2006), it seems difficult to think about these huge differences between countries with respect to inequality and redistributive policy without any reference to differences in such beliefs and perceptions. In the model of Bénabou and Tirole (2006), people hold different beliefs about the determinants of economic success and the reward of own effort. If a majority of people thinks that own effort is decisive of success, then they will vote for a low level of redistribution because they are not in need of redistribution. A low level of redistribution in turn will strengthen individuals' incentives to choose a high level of effort, which will therefore also strengthen their belief in that own effort will ultimately pay out. In the model of Alesina and Angeletos (2005), individuals' beliefs about the determinants of income inequality determine redistributive policies by choosing the tax rate, and redistributive policies in turn determine the actual amount of inequality, which then feeds back on individuals' perceptions and attitudes. Both of these models give rise to multiple equilibria and therefore are able to give a stylized explanation for the difference in attitudes, but also in policies, across countries. $^{2}$ The potential feedback from incentives created by any redistributive scheme to

\footnotetext{
${ }^{1}$ Similarly, Di Tella and MacCulloch $(2002,2004)$ argue that the level of unemployment benefits is determined by workers' desire for insurance against the risk of unemployment.

${ }^{2}$ Both models contrast the European experience with that from the United States. Indeed, empirical studies tend to find marked differences in attitudes and beliefs between Europe and the United States. For example, Alesina et al. (2004) show that there are differences as regards who is concerned about inequality. In Europe, they find that mostly the poor and people on the left are unhappy about inequality, while in the United States it is the rich individuals who are unhappy about inequality. On the other hand however, Osberg and Smeeding (2006) argue that Americans do not really have different attitudes about inequality than Europeans on average,
} 
individuals' attitudes and norms over redistribution has also been pointed out by Korpi and Palme (1998).

As regards the hypothesized link between individuals' beliefs and attitudes to economic or political outcomes, there are several empirical studies provide evidence in support of such a line of argument. For example, Di Tella et al. (2007) study how economic endowments change individuals' market beliefs, studying a natural experiment near Buenos Aires which randomly granted legal land titles to some squatters while not to some others. They find that the lucky squatters - those who were entitled legal land titles - exhibit more materialist and individualistic beliefs later on; beliefs which are assumed to be favorable to a market economy. In a similar take, Di Tella et al. (2008) study the manipulation of beliefs and the conditions under which beliefs can be manipulated in the context of the re-nationalization of the main water company in Argentina. The other way round, it has been shown that social norms - i.e. the norm to earn his own living - affect individuals' unemployment behavior (Clark, 2003). For example, Stutzer and Lalive (2004) show that social norms can affect individuals' behavior in turn. Specifically, they use regional variation in a referendum on the level of unemployment benefits in Switzerland as measure for the norm to work and not live off public benefits as to show that the social norm to work influences the average duration of unemployment. It turns out that unemployed individuals do find a job more quickly in those regions where the social norm to work is high. Abramitzky (2008) provides additional insight into the delicate interplay between social norms and economic incentives in the context of Israeli kibbutzim.

The idea that the actual amount of redistribution is linked to individuals' preferences over redistribution is also born out by the available empirical literature studying the determinants of individual demand for redistribution. Fong (2001) models the support for redistribution, measured on a scale ranging from 1 to 6 , as a function of beliefs about the determinants of pay and controls for self-interested redistribution using survey data from the U.S. She finds that people's beliefs about the determinants of pay have large and significant effects, even after controlling for variables describing self-interested motives for redistribution, most importantly the own the level of income. Although income does predict some of the variation in the support for redistribution, it is a surprisingly poor predictor on itself, given its prominent role in the economic literature. Similarly, Corneo and Grüner (2002) also show that the support for redistribution is driven by selfish motives, but not exclusively so. They also find that people seem to share a common belief in distributive justice, and that individuals' attitudes and perceptions are relevant for shaping preferences for redistribution. Moreover, they also show that status concern, i.e. relative comparisons, is an additional determinant of the demand for redistribution. Similar results are presented in Alesina and La Ferrara (2005) and in Alesina and Giuliano (2009). On top of the arguments already laid out, the former study additionally stresses the impact of expected changes in income in the future, which is likely to be linked to past experience of social mobility. The latter study emphasizes the potential role of cultural and historical factors in explaining the variation in preferences over redistribution.

but that they only differ in more subtle ways from European citizens. As an example, they present evidence that there is less concern about the bottom of the wage distribution in the United States than in Europe. 
The potential feedback from political and economic institutions is the focus of Alesina and Fuchs-Schündeln (2007). They study the effect of the German separation and reunification on individuals' attitudes towards state intervention. Not surprisingly, they find that East Germans are much more supportive of state intervention than West Germans. They also argue though that East Germans' attitudes will converge towards those of West Germans within the course of some generations. Corneo and Fong (2008) go one step further and estimate individuals' willingness-to-pay for distributive justice, again using data for the United States. They show that the people put a substantial monetary value on redistribution, and that differences across individuals are driven by differences in income, but also in differences in beliefs and norms that people hold.

However, less is known about the forces that shape the demand for redistribution in the first place. That is, we do not really know whether individuals demand redistribution because they want to increase the lowest wages or because they would like to decrease the highest wages, or whether it is driven by misperceptions of real pay differentials or because their normative standards are violated. Moreover, empirical evidence on the hypothesized link between the demand for redistribution and political outcomes is almost completely lacking. ${ }^{3}$ In this paper, I therefore try to add to the literature mainly by proposing a simple, yet very intuitive, conceptual framework which is suitable for measuring individuals' evaluations of wage inequality and their demand for redistribution. In the empirical part of the paper, I apply the framework using data from the International Social Survey Program (ISSP). The framework explicitly distinguishes between individuals' perception of the factual distribution of wages on the one hand and their evaluation of the desired distribution of wages on the other hand. The discrepancy between these two variables is then used for measuring the demand for redistribution at the individual level. This conceptualization explicitly recognizes that individuals might differ both in their perception of the factual distribution and in their belief about the distribution they judge as legitimate. Demand for redistribution can thus only arise if the perceived level of inequality diverges from the desired level of inequality. The paper will also explore the anatomy of the demand for redistribution, i.e. I will explore whether the demand for redistribution is primarily driven by desired changes at the bottom or the top end of the wage distribution or both, eventually. Analogously, the demand for redistribution can be understood as the interplay between the perception of the actual wage inequality and the belief about how wage inequality ideally should look like. Second, I will study the importance of various factors in explaining the observed variation in the support for redistribution. Specifically, I will explore the question of whether and to what extent these differences can be attributed to either self-interest, to perceptions of how wages are set in reality and social norms over distributive justice, or to both of them. Fourth and finally, the paper will explore the empirical link between the demand for redistribution on the one hand

\footnotetext{
${ }^{3}$ At the aggregate level, there is some evidence that welfare retrenchment (i.e. cutting back unemployment or sickness benefits) is associated with partisan politics, see Allan and Scruggs (2004) and Korpi and Palme (2003). At the individual level, there is some evidence that values are associated with party identification (Goren, 2005) and that party identification is in turn related to individuals' voting behavior (Beck et al., 2002).
} 
and stated preferences over political parties on the other hand and thereby provide indirect empirical evidence on the hypothesized link between beliefs and political outcomes. One of the main goals of this paper is to establish some indirect empirical evidence on the hypothesized link between individuals' perceptions and beliefs and political outcomes and thus finally the factual amount of inequality. To this end, I chose to exclusively focus on Switzerland in the empirical part of the paper. Switzerland seems an ideal candidate because there are more than two decisive political parties, and these parties differ strongly in their point of view as regards redistributive policy (Feld and Kirchgässner, 2000). Second, Swiss citizens are not only involved in regular elections, but they are also asked to regularly poll their vote for the many referenda and initiatives that are held each year and which often involve issues that directly touch on issues of redistribution (Feld and Matsusaka, 2003).

The main empirical findings of this paper may be summarized as follows. First, there is considerable support for at least some redistribution of wages. That is, there is support for at least some equalization of wages, resulting from the fact that the desired inequality in wages is on average considerably lower than the perceived inequality in wages. At the same time however, most people accept rather large differences in wages between different occupations. Second, and consistent with previous evidence, self-interest, perceptions of how wages are determined in reality, and attitudes about distributive justice all do explain some variation of the individual support for redistribution. Third, I also find empirical evidence on the link between the demand for redistribution and party identification and thus indirect evidence on the potential feedback from norms and beliefs to political outcomes (e.g. tax rates). Indeed, the demand for redistribution turns out to be a strong predictor of individuals' support for the welfare state (i.e. individuals' support for redistribution by the state) and subjective inequality measures also have quite some power in predicting individuals' stated preferences for different political parties.

The remainder of this paper is structured as follows. Section 2 describes the data source along with the key variables on individuals' estimates of occupational wages. In section 3, I discuss the conceptualization and the measurement of subjective measures of wage inequality and individuals' demand for redistribution. Section 4 presents extensive descriptive results, stressing the diversity of perceptions and beliefs that people hold. Section 5 presents some simple regression models which link individuals' attitudes towards distributive justice and perceptions of inequality to their demand for redistribution. Further, more detailed results look along the dimension of perceived versus desired wage inequality and along the dimension of top versus bottom of the wage distribution, respectively. In section 6 , I present and discuss empirical evidence on the hypothesized link between the demand for redistribution and support for the welfare state and party identification, respectively. Section 7 concludes. 


\section{Data}

I use data from the International Social Survey Program (ISSP, 1999). The ISSP is an international collaboration of several national survey organizations which aims at conducting annual cross-national survey collaborations. The program focuses on different thematic topics each year like, for example, the environment, religion, or the role of government. In 1987, the ISSP administered its first survey on issues of social inequality. The corresponding survey provides data on individuals' perceptions of the income distribution and the factors determining individual incomes, issues of distributive justice as well as the role of the government regarding the distribution of incomes. Two more surveys on the same main topic followed in 1992 and 1999, and a fourth survey is under way in 2009.

As mentioned in the introduction, I focus exclusively on the data from Switzerland for the empirical analysis in this paper. Stamm et al. (2003) provide many more details regarding the collection of the data and an extensive descriptive discussion of the data (the data can be obtained from the Swiss Information and Data Archive Service for the Social Sciences, study no. 6396). The selection of the sample used in the analysis is primarily driven by missing data and thus basically by the selection of the variables that I will use in the subsequent empirical analysis. For reasons of comparability and consistency, all results to follow are confined to the same sample of observations providing full information on the dependent variable and all independent variables. There ultimately remain about 590 observations providing full information on both the dependent variables and the full set of regressors, out of the original 1,258 observations. Although there are some slight differences between the sample used in the analysis and the observations not included due to missing data, appendix C.1 shows that the quantitative results are not strongly affected by sample selection due to missing data, and thus that the qualitative results are therefore not driven by sample selection.

\subsection{Individuals' Estimates of Occupational Wages}

The most interesting part of the survey certainly is a battery of questions about subjective estimates of the wages of people working in different occupations like an unskilled worker in a factory, for example. ${ }^{4}$ Individuals were asked to estimate what they thought to be the actual monthly net wage (i.e. the wage net of social security contributions, but before taxes and transfers, in Swiss francs) of people who are working in nine different occupations plus their coworkers. Implicitly, all wage estimates refer to full-time employment, such that differences in wages do not reflect differences in working hours. Second, they were asked to estimate what they thought people working in these occupations should - in their very own and subjective view - earn net per month. ${ }^{5}$ In what follows, I will refer to these wage estimates as actual

\footnotetext{
${ }^{4}$ The full list of occupations and the exact wording of the questions is given in appendix A. Kelley and Evans (1993) provide an interesting international comparison of such occupational wages using data from an earlier survey of the ISSP.

${ }^{5}$ The demand for redistribution will be conceptualized as the discrepancy between actual and just wages (see section 3). As a consequence, there is a little twist in using these data for evaluating the demand for redistribution because both actual and just wages are asked for before taxes and transfer payments (note that
} 
(perceived) and just (desired, ethical) wages, respectively.

Importantly, note that I am not concerned with factual occupational wages in this paper, and that individuals' estimates of actual occupational wages need not necessarily be the same as the true occupational wages. ${ }^{6}$ Nonetheless, these wage estimates allow me to examine differences between individuals' perceptions of actual compensation and the level of compensation that they would judge as appropriate for the nine different occupations and moreover, in a certain way, I am even making a virtue out of necessity because I will explicitly allow individuals' misperceptions of reality to be one important channel in the framework which I will use later on.

\section{Table 1}

Descriptive statistics for these individual wage estimates are given in table 1 . The first column shows average estimates of actual wages, while the second column shows average estimates of just wages. Table 1 tells us, for example, that people on average think that an unskilled worker in a factory earns about 3,200 CHF a month. At the same time, they also think that people working in this occupation ought to be paid about 3,900 $\mathrm{CHF}$, or about 700 CHF more than the perceived actual wage. Similarly, as regards a lawyer, the average estimate of his actual wage amounts to about 18 thousand $\mathrm{CHF}$, while the average estimate of his ethical wage is about 13 thousand CHF. Figure 1 makes this feature of the data visible. ${ }^{7}$ Individuals' estimates of their coworkers' wages are interesting on their own because they may be used as an evaluation of whether they perceive their own pay to be fair or not. Most people actually tend to judge the wage of their coworkers - and thus presumably their own wage also - as appropriate, and that this judgment appears virtually independent of the absolute level of compensation. In fact, about $38 \%$ of the individuals gave exactly the same estimate for the actual and the desired wage of their coworkers. ${ }^{8}$ Some few individuals even state that their coworkers' wage should be lower than its actual level. Still, most respondents would like a higher wage than perceived, the average respondent would judge a wage about $13 \%$ higher than his actual wage as appropriate for him- or herself (for his coworkers, respectively).

Figure 1

'net wage' in Switzerland corresponds to gross wage net of mandatory social security contributions only). The total amount of desired redistribution in occupational wages would be given by comparing actual gross wages with desired net wages (i.e. wages after taxes and transfers), which would capture the total desired reduction (or increase, respectively) due to redistributive measures. Because I can only compare wages before taxes and transfers, I can only capture redistribution on top of the redistribution already implemented implicitly by the current system of taxes and transfers literally.

${ }^{6}$ Interestingly, Stamm et al. (2003, p.166) note that average wage estimates and factual wages are surprisingly close. For example, average monthly wages of a salesperson and a skilled factory worker equal 3,030 and 4,660 CHF, respectively (according to the Swiss Labor Force Survey of the years 1998/99). Note how close these numbers are to the corresponding numbers of table 1 (about 3,000 and 4,200 CHF).

${ }^{7}$ On top, figure D.1 in the appendix shows density estimates of the full distribution of these wage estimates, separately for each occupation.

${ }^{8}$ Another question in the survey directly asked "Do you think that your wage corresponds to your effort and your skills?" More than $50 \%$ of the individuals in the sample think that their wage is appropriate in this sense. 
Taken together, table 1 and figure 1 show three important points. First, there is a clear ranking of the different occupations with respect to the average estimate of their actual monthly wages, from a low of about three thousand CHF (the wage of a shop assistant) to a high of more than thirty thousand CHF (the wage of a chairman of a large national company). Interestingly, almost the same ranking of occupations holds with respect to ethical wage estimates. The first remarkable feature of the data therefore is thus the fact that most individuals seem to accept rather large differentials in pay between different occupational groups. Note that this also implies that absolute equality - equal wages for all occupations - does not seem not to be judged as a fair distribution neither. ${ }^{9}$ Second, most people are prone to equalize wages to a quantitatively important degree, as evident from panel (a) of figure 1. Within each occupation, average estimates of actual wages are different from average estimates of desired wages, the sign and magnitude of this difference varies across the occupations however. The third key feature is the obvious dichotomous grouping of the nine different occupations with respect not only to the average estimate of actual and ethical pay, but also with respect to the desired change in pay. It is evident that average estimates of just wages are higher than average actual wages for those three occupations with the lowest estimated actual wages (i.e. shop assistant, unskilled and skilled worker). The reverse holds true for the occupations with high average estimates of actual wages. Specifically, there is one group of occupations (the three blue-collar jobs: unskilled worker, skilled worker and salesman) for which there is a positive average difference between the two estimates and another group of occupations (all other professions, leaving out one's own occupation) for which this difference is negative on average. In what follows, the first group of professions will be referred to as the low-wage group (or bottom group) and the second as the high-wage group (or top group).

Another interesting observation relates to the variation of the wage estimates within and across occupations. Table 1 and panel (b) of figure 1 show that the occupations not only differ with respect to the average estimate, but also with respect to the dispersion of these estimates across individuals. First, the observed variation of the estimates (both actual and desired wages) for some occupations are larger than for the others (this holds true even if taking account of the difference in the level of the estimates). In particular, there is a very clear distinction between the blue-collar and the white-collar occupations, presumably reflecting the fact that most people have no real connection to people working in these occupations. Second, the dispersion of actual estimates is in fact higher than the dispersion in desired wages for most of the occupations (see table 1 again), somehow suggesting that people's perceptions are actually more dispersed than their beliefs. Consequently, comparing wage estimates not only within occupations but also across occupations, we see that the overall distribution of just estimates shows higher dispersion than actual wage estimates (also due to the fact that average estimates are closer in the case of just wages). ${ }^{10}$ More interestingly, the dispersion in

\footnotetext{
${ }^{9}$ In fact, focusing only on those individuals who gave estimates for all nine occupations, only two of them gave exactly the same estimate for all occupations.

${ }^{10}$ This is confirmed by comparing any measure of dispersion. For example, the Theil index evaluated over the distribution of all actual wage estimates yields a value of 0.3865 and a value of 0.2990 with respect to the
} 
the desired wage changes is notably larger for the high wage group than the low wage group, presumably reflecting the fact that in general both actual and desired wages of the high wage group are more dispersed than the corresponding wages of the low wage group.

\section{Conceptual Framework}

The key feature of the framework I propose is the distinction between the level of wage inequality that individuals perceive to exist on the one hand, and the level of inequality that they are prepared to accept on the other hand. This distinction is not now however. Indeed, researchers from different fields have pointed out that fairness evaluations must always be relative to some reference point. Jasso has published a series of papers on this issue (Jasso, 1978, 1980, 1999), arguing that distributive justice is essentially a relational concept. Similar arguments have been put forth by Alwin (1987), Shepelak and Alwin (1986), and Younts and Mueller (2001). More recently, Osberg and Smeeding (2006) have used an conceptual and empirical framework similar to the one proposed here. This point is nicely described by Sen (2000, p.60), who points out that "people's attitudes towards, or reactions to, actual income distributions can be significantly influenced by the correspondence - or lack thereof - between (1) their ideas of what is normatively tolerable, and (2) what they actually see in the society around them".

Such a conceptualization allows that people differ in their support for redistribution, even if they share the same perception, as long as they differ in their evaluation of the just inequality. On the other hand, individuals with the same evaluation of the ethical level of wage inequality may still differ in their support for redistribution as soon as they have different perceptions about the factual distribution of wages. Support for redistribution may thus arguably only arise if these two evaluations differ from each other, but differences between individuals may either be driven by different perceptions or by differences in their normative evaluations, or both. In this sense, both the evaluation of occupational wage inequality and the demand for redistribution are specific to each individual and therefore, ultimately, in the eye of the beholder.

\subsection{Individual-Level Data}

The second feature of my framework is that I borrow from methods that are usually applied to the measurement of inequality as regards objective wage data. A useful and natural starting point therefore is the measurement of wage inequality in an objective sense. Let $y_{[n]}$ be the vector of individual wages for some random sample of size $n$, indexed by $i=1, \ldots, n$ :

$$
y_{[n]}=\left\{y_{(1)}, \ldots, y_{(i)}, \ldots, y_{(n)}\right\} \text {, }
$$

with $y_{(1)} \leq y_{(2)}, \ldots, y_{(n-1)} \leq y_{(n)}$. Therefore, $y_{(1)}$ denotes the wage of the poorest individual in the sample. Note that is is, in principle, sufficient to observe $y_{[n]}$ in order to measure

distribution of just wage estimates (excluding coworkers' wages in both cases). 
wage inequality in any given sample because $y_{[n]}$ fully describes the wage distribution within the sample and because most inequality measures are some function of $y_{[n]}$ only (e.g. Cowell, 2000). ${ }^{11}$

Measuring subjective wage inequality, i.e. measuring wage inequality at the individual level, is conceptually a simple task. In principle, it only requires that the vector of wages is allowed to depend on the evaluation of individual $i$ and therefore to differ across different individuals:

$$
y(i)_{[n]}^{w}=\left\{y(i)_{1}^{w}, \ldots, y(i)_{i}^{w}, \ldots, y(i)_{n}^{w}\right\},
$$

where the second index $w$ also introduces the distinction between perceived and ethical wages, with $w=a$ referring to actual wage estimates and $w=j$ referring to just wage estimates of invidual $i$, respectively. ${ }^{12}$ From this point of view, the measurement of objective wage inequality may actually be regarded as a special case of (2), where each individual only gives an estimate of his or her own actual wage.

Given individual evaluations for both actual and desired wages, it's straightforward to define the individual demand for redistribution as the desired reduction in occupational wage inequality, relative to one's perceived level of actual inequality: ${ }^{13}$

$$
R(i)=-1 \cdot\left[\frac{I(i)^{j}-I(i)^{a}}{I(i)^{a}}\right]
$$

with $R(i)=0$ denoting that an individual does not demand any redistribution at all, because her perceived level of occupational wage inequality is exactly the same as the what she judges as an just level of inequality. In turn, $R(i)=1$ corresponds to the case where she would like to eliminate all differences in occupational wages, irrespective of her perception. Summing over all individuals yields a matrix of wage estimates of size $(n \times n)$ overall. Because each individual gives his estimate of the the whole distribution of occupational wages, individual measures of inequality can be computed, resulting in a distribution of inequality measures for a given sample of individuals (as compared to one inequality measure only in the case of objective wage data). The obvious problem now becomes one of practicability: Each individual would have to estimate $n$ potentially different wages - a task which surely is not feasible in practice,

\footnotetext{
${ }^{11}$ For simplicity, I leave any sampling issues aside, focusing exclusively on conceptual issues. However, it is obvious that under simple random sampling and as the sample size grows, the sample distribution of $y_{[n]}$ converges to the population wage distribution $y$. This in turn implies that sample inequality measures also converge to the corresponding population inequality measures.

${ }^{12}$ For simplicity, I assume for the moment that the ordering of the individuals in equation (2) is the same as the order in equation (1). For example, $y(i)_{1}^{a}$ denotes individual $i$ 's estimate of the actual wage of that individual with the lowest factual wage and, similarly, $y(i)_{1}^{j}$ denotes what $i$ would judge as an ethical wage for that very same person.

${ }^{13}$ Alternatively, one could also use the simple difference in the two inequality measures for any given individual:

$$
\Delta I(i)=-1 \cdot\left[I(i)^{j}-I(i)^{a}\right]=\left[I(i)^{a}-I(i)^{j}\right]
$$

as a measure for the demand for redistribution. Although I will focus on (3) later, I will nonetheless present some results based on the difference of the two corresponding Gini coefficients.
} 
even for moderate sample size.

\subsection{Group-Level Data}

One possible solution to this problem is to reduce the number of wage estimates any given individual has to make and therefore to rely on group-level data instead of individual-level data. To illustrate how this works, I go back to the measurement of objective inequality. The 'true' wage distribution, as given by equation (1), can be approximated using group-level wages only:

$$
y_{[k]}=\left\{\left(\bar{y}_{(1)}, f_{(1)}\right), \ldots,\left(\bar{y}_{(j)}, f_{(j)}\right), \ldots,\left(\bar{y}_{(k)}, f_{(k)}\right)\right\},
$$

where $j=1, \ldots, k$ indexes groups (with $k<n$ ), $\bar{y}_{(j)}$ denotes the average wage within group $j$, and $f_{(j)}$ denotes the population weight of group $j$ with $\sum_{j=1}^{k} f_{(j)}=1$. Knowledge of $y_{[k]}$ allows to approximate the individual wage distribution, given by $y_{[n]}$, and thus allows to approximate wage inequality in the sample without the need to observe the whole distribution of individual wages. Obviously, the approximation is the better, the larger the number of groups and the smaller the variation of wages within groups. ${ }^{14}$

As before, measuring subjective evaluations of the wage distribution implies that we make the vector of group-level wages dependent on individual $i$ 's evaluation:

$$
y(i)_{[k]}^{w}=\left\{\left(\bar{y}(i)_{1}^{w}, f(i)_{1}^{w}\right), \ldots,\left(\bar{y}(i)_{j}^{w}, f(i)_{j}^{w}\right), \ldots,\left(\bar{y}(i)_{k}^{w}, f(i)_{k}^{w}\right)\right\}
$$

with $w=a$ referring to actual and $w=j$ to just wage estimates, respectively. As before, group level wage estimates are thought to be ordered in the same way as in equation (4), such that the ranking of the groups is the same for each individual. The reduction in the dimension of the number of estimates per individual $k$ now introduces the problem that the weights of the different groups must also be estimated by individual $i$ if we want to make any statements about the wage distribution as a whole, and there still remain $2 k$ parameters to be estimated by any given individual.

Because I want to focus exclusively on differences in the evaluation of wages in what follows, and because people seem to be notoriously uncertain in estimating such shares, I simplify the problem further by fixing the population weights across individuals and between actual and just wage estimates for any given individual: ${ }^{15}$

$$
y(i)_{[k]}^{w}=\left\{\left(\bar{y}(i)_{1}^{w}, f_{1}\right), \ldots,\left(\bar{y}(i)_{j}^{w}, f_{j}\right), \ldots,\left(\bar{y}(i)_{k}^{w}, f_{k}\right)\right\}
$$

\footnotetext{
${ }^{14}$ In the limit, as $k \rightarrow n$, we obviously have $y_{[k]} \rightarrow y_{[n]}$. For a given number of groups $k<n$, the approximation is the better, the less within-group variation in wages there is. If there is no within-group variation in wages at all, then $y_{[k]}=y_{[n]}$, even if the number of groups $k$ is smaller than the number of observations $n$. If there is variation within groups, the Gini coefficient based on group-level data will underestimate the true Gini coefficient based on individual-level data (see, inter alia, Kakwani and Podder, 1973).

${ }^{15}$ In terms of equations (2) and (5), fixing the group weights may simply be understood as requiring that each individual estimates the wages for exactly the same sample of individuals. From this point of view, it seems natural to fix the population weights across individuals.
} 
This additional step considerably simplifies the original task because now each individual has to estimate $k$ (instead of the original $n$ ) different wages only. In the most simple case, the case on which I will focus later on, only two different groups (which I'll label bottom group and top group, respectively) are considered:

$$
\begin{aligned}
y(i)_{[2]}^{w} & =\left\{\left(\bar{y}(i)_{\mathrm{bottom}}^{w}, f_{\mathrm{bottom}}\right),\left(\bar{y}(i)_{\mathrm{top}}^{w}, f_{\mathrm{top}}\right)\right\} \\
& =\left\{\left(\bar{y}(i)_{\mathrm{bottom}}^{w}, f_{\mathrm{bottom}}\right),\left(\bar{y}(i)_{\mathrm{top}}^{w},\left(1-f_{\text {bottom }}\right)\right)\right\}
\end{aligned}
$$

In this case, each individual has to estimate only two different wages. Furthermore, since the group weights must always sum to 1 , only one weight needs to be fixed explicitly.

\subsection{Occupational Wage Estimates Reconsidered}

The occupational wage estimates, which have been discussed in section 2.1, almost perfectly fit into this framework because they can be transformed into a form equivalent to equation (7). To do so, I first group the nine original occupations into two broader groups. Section 2.1 has shown that there is a clear distinction between the nine occupations for which wage estimates were asked for. I exclude coworkers' wages in the following, because these estimates refer to different occupations for different individuals. Specifically, I group the nine occupations into two distinct sets: ${ }^{16}$

$$
\begin{aligned}
\text { bottom } & =\{\text { shop assistant, unskilled worker, skilled worker }\} \\
\text { top } & =\{\text { doctor, lawyer, judge, minister, owner of a factory, chairman }\}
\end{aligned}
$$

The first group of occupations consists of the three blue-collar occupations which are characterized by low wage estimates on average with respect to both actual and ethical wages. I thus view this group of occupations as representing the lower part of the occupational wage distribution. The other group of occupations consists of the remaining six white-collar occupations. These occupations are characterized by high average estimates with respect to both actual and ethical wages. They can therefore be viewed as representing the upper end of the occupational wage distribution. Moreover, the occupations in the bottom (top) group can further be characterized by a positive (negative) ratio of ethical to actual wage estimate on average. According to this grouping, I then estimate the mean wages of individuals from the

\footnotetext{
${ }^{16}$ There are several different reasons for aggregating wage estimates over different occupations. First, I have to make some additional assumption about the frequencies of the different occupations anyway in order to fit the framework laid out before. This is most easily done for two groups of occupations only because only two population weights need to be assumed or estimated in this case. Note that some of the occupations for which individuals gave wage estimates have very low or almost zero frequencies in the whole population (e.g. a member of the Swiss Federal Council). Also, although estimates for some specific occupations may be largely off the mark, average estimates over several occupations may still give a reliable estimate of what an individual perceives to be the wage of such a broader group. Further, the problem of missing data (on the dependent variable) can be mitigated to some extent as averaging over several occupations allows me to compute subjective inequality measures as long as an individual gave at least one wage estimate for each of the two sets of occupations (also see appendix C.1).
} 
lower and the upper tail of the occupational wage distribution as follows:

$$
\bar{y}(i)_{\mathrm{bottom}}^{w}=\frac{\sum_{j=1}^{9} \mathbb{1}(j \in \operatorname{bottom}) y(i)_{j}^{w}}{\sum_{j=1}^{9} \mathbb{1}(j \in \text { bottom })}
$$

and

$$
\bar{y}(i)_{\mathrm{top}}^{w}=\frac{\sum_{j=1}^{9} \mathbb{1}(j \in \mathrm{top}) y(i)_{j}^{w}}{\sum_{j=1}^{9} \mathbb{1}(j \in \mathrm{top})}
$$

where $\mathbb{1}(\cdot)$ denotes the indicator function and $w$ again refers to either actual $(w=a)$ or just $(w=j)$ wage estimates. Moreover, $j=1, \ldots 9$ indexes the nine different occupations for which subjective wage estimates are available in the data.

Finally, I need some estimate of the population share of the bottom group, $f_{\text {bottom }}$ (because the two population weights are fixed across individuals, I only need one single estimate of $\left.f_{\text {bottom }}\right)$. The natural choice is to estimate $f_{\text {bottom }}$ from the occupational distribution in the sample, using the International Standard Classification of Occupations (ISCO): ${ }^{17}$

$$
f_{\text {bottom }}=\frac{1}{n} \sum_{i=1}^{n} \mathbb{1}\left(\mathrm{ISCO}_{i} \in[3,9]\right),
$$

where $\mathrm{ISCO}_{i}$ corresponds to the major ISCO-code of individual $i$ 's occupation. The upper part of the occupational distribution thus, by assumption, only comprises ISCO-codes 1 ('legislators, senior officials and managers') and 2 ('professionals'). All remaining occupations are assumed to be part of the lower end of the occupational distribution therefore. Because the universe of occupations is divided into two groups only, $f_{\text {top }}=\left(1-f_{\text {bottom }}\right)$.

\subsection{Subjective Measures of Occupational Wage Inequality}

Up to this point, the following two triples of information are observed for each individual in the sample:

$$
\begin{aligned}
& \left(\bar{y}(i)_{\text {bottom }}^{a}, \bar{y}(i)_{\text {top }}^{a}, f_{\text {bottom }}\right), \quad \text { and } \\
& \left(\bar{y}(i)_{\text {bottom }}^{j}, \bar{y}(i)_{\text {top }}^{j}, f_{\text {bottom }}\right)
\end{aligned}
$$

These data are in a form that fits the conceptualization given by equation (7), and they therefore provide a rough approximation to the whole occupational wage distribution for any given individual. The data in the form of equation (10a) are used to describe the occupational wage distribution as perceived any given individual and the data in the form of equation (10b) describe the distribution of wages that is judged as fair by a given individual. Importantly, note again that $f_{\text {bottom }}$ is treated as a fixed parameter, which implies that it does neither vary across individuals nor between the evaluation of the actual and the desired wage distribution for any

\footnotetext{
${ }^{17}$ Appendix $\mathrm{C}$ shows that the exact choice of $f_{\text {bottom }}$ is not crucial for the results.
} 
given individual. Given individual estimates of group-specific wages and the population weight of the bottom group, it is straightforward to construct an estimate of the overall population wage:

$$
\bar{y}(i)^{w}=\bar{y}(i)_{\mathrm{bottom}}^{w} \cdot f_{\mathrm{bottom}}+\bar{y}(i)_{\mathrm{top}}^{w} \cdot f_{\mathrm{top}}
$$

Because the two population weights are the same not only between individuals but also for the evaluation of the actual and the desired distribution, all observed differences between individuals' estimates of $\bar{y}(i)^{a}$ and $\bar{y}(i)^{j}$ must therefore necessarily be due to differences in the underlying wage estimates. The same holds true for all differences between $\bar{y}(i)^{a}$ and $\bar{y}(i)^{j}$ for any given individual.

Table 2, panels (a) and (b)

Descriptive statistics for these overall wage estimates are given in panels (a) and (b) of table 2. Panel (a) refers to the actual distribution of occupational wages, while panel (b) refers to the distribution of ethical wages. The two panels show essentially the same pattern that we have already seen in figure 1 , although in a more condensed way. First, $f_{\text {bottom }}$ is estimated to be about $77 \%$ and thus $f_{\text {top }}$ to about $23 \% .{ }^{18}$ Average group wages equal about 3,450 and 22,600 CHF per month for the bottom and the top group, respectively. The overall actual wage estimate of about $7,800 \mathrm{CHF}$ per month. Ethical wage estimates equal about 4,300 CHF for the bottom group and about 16,759 for the top group, resulting in an overall ethical wage estimate of about 7,100 CHF per month. Wage estimates for the bottom group are thus on average lower than the corresponding estimates for the top group and the ratio of ethical to actual average wage estimates of positive for the bottom group and negative for the top group. As regards perceived wages, the average wage estimate for the top group is about 6.5 times higher than the wage estimate for the bottom group. With respect to ethical wages, the average estimate for the top group is still about 2.3 times higher than the corresponding estimate for the bottom group. Because the desired decrease in the wage of the top group is larger than the desired increase of the bottom group in relative terms, the overall ethical wage estimates is somewhat smaller than the overall actual wage estimates.

Moreover, these three statistics are sufficient so as to compute the relative wage share of the bottom group: ${ }^{19}$

$$
q(i)_{\mathrm{bottom}}^{w}=\left(\frac{\bar{y}(i)_{\mathrm{bottom}}^{w} \cdot f_{\mathrm{bottom}}}{\bar{y}(i)^{w}}\right)=\left(\frac{\bar{y}(i)_{\mathrm{bottom}}^{w} \cdot f_{\mathrm{bottom}}}{\bar{y}(i)_{\mathrm{bottom}}^{w} \cdot f_{\mathrm{bottom}}+\bar{y}(i)_{\mathrm{top}}^{w} \cdot\left(1-f_{\mathrm{bottom}}\right)}\right)
$$

which in turn is all that is needed to construct the corresponding Gini coefficient along with the corresponding population weights. It's easy to show that the Gini coefficient, based on group-level data, is given by the following simple expression in the present case of two different

\footnotetext{
${ }^{18}$ Appendix C.2 shows that the choice of population weights is not important for the qualitative pattern of the results, and it does not even impact the results in quantitative terms by much.

${ }^{19}$ Because the wage shares of the two groups have to sum up to 1 , the wage share of the top group is immediately given by $q(i)_{\text {top }}^{w}=1-q(i)_{\text {bottom }}^{w}$.
} 
groups only (see appendix B):

$$
G(i)^{w}=f_{\text {bottom }}-q(i)_{\text {bottom }}^{w},
$$

where $w=a$ and $w=j$ again refers to the perceived and the ethical wage distribution, respectively. Thus, $G(i)^{a}$ thus describes the inequality in occupational wages as perceived by individual $i$ and $G^{j}$ describes the ethical level of wage inequality as evaluated by individual $i$. Obviously, the Gini coefficient is zero only if the wage share is equal to the population share and it reaches its maximum when the wage share is estimated to be zero. ${ }^{20}$ Because $f_{\text {bottom }}$ is the same for both the actual and the just inequality measure for any individual, the only reason for any difference between actual inequality $\left(G^{a}\right)$ and ethical inequality $\left(G^{j}\right)$ are differences in the wage estimates.

Because the population share $f_{\text {bottom }}$ is the same for all individuals, all variation in the subjective Gini coefficient is due to variation in the evaluation of occupational wages. Equation (13) makes it also clear that different estimates of the population weights will result in different subjective inequality measures. However, the choice of $f_{\text {bottom }}$ does not change the ranking of individuals with respect to these measures and, therefore, it has no impact on the qualitative results (this point is further discussed in appendix C.2). Further, the maximum value of $G^{w}$ also depends on the estimate of $f_{\text {bottom }}$ (i.e. $G^{w}=f_{\text {bottom }}$ for $q(i)_{\text {bottom }}^{w}=0$ ), and the range of possible values for $G^{w}$ is therefore not the unit interval (as it would be using individual-level data). ${ }^{21}$

Finally, I define the demand for redistribution simply as the desired reduction in occupational wage inequality, relative to the perceived level of wage inequality:

$$
R(i)=-1 \cdot\left[\left(\frac{G(i)^{j}}{G(i)^{a}}\right)-1\right]=\left[1-\frac{G(i)^{j}}{G(i)^{a}}\right]
$$

$R(i)$ measures the extent to which people would like to decrease (or increase, eventually) the level of wage inequality, as a percentage of the perceived factual wage inequality. $R(i)$ combines the perceived and the desired level of wage inequality and fits our basic intuition about the demand for redistribution. Demand for redistribution increases, ceteris-paribus, when the perceived wage inequality is high or when the desired level of wage inequality is low, as we obviously have that $\frac{\partial R}{\partial G^{j}}=-\frac{1}{G^{a}}<0$ and $\frac{\partial R}{\partial G^{a}}=\frac{G^{j}}{\left(G^{a}\right)^{2}}>0$. At the same time, no matter how high or how low the perceived level of inequality is, redistribution is only supported if there is any discrepancy between the perceived and the desired level of wage inequality.

\footnotetext{
${ }^{20}$ Note that the Gini coefficient could actually be negative if the wage share of the bottom group would be larger than $f_{\text {bottom }}$, which is not ruled out a priori. However, this case is not observed at all in the data.

${ }^{21}$ This could easily be fixed by dividing $G^{w}$ by $f_{\text {bottom. }}$. To see why this works, note that the maximum value of the Gini coefficient in the case of group-level data is given by:

$$
G^{\mathrm{max}}=\left[\frac{1 \cdot 0.5 \cdot\left(1-f_{\mathrm{top}}\right)}{0.5}\right]=\left(1-f_{\mathrm{top}}\right)=f_{\mathrm{bottom}},
$$

which follows from the fact that $\left(f_{\text {bottom }}+f_{\text {top }}\right)$, and therefore the maximum value of $G$ is given by the relative population size of the bottom group.
} 


\section{The Diversity of Perceptions and Beliefs}

Descriptive statistics for the three subjective inequality measures as well as for the demand for redistribution are given in panel (c) of table 2. As discussed before, the average actual wage estimate is lower than the average ethical wage estimate for the bottom group. That is, the average individual would like to increase the wage of this group. On the other hand, people would like to decrease the wage of the high wage group. Irrespective of the chosen population weights, people therefore demand some reduction of the wage inequality as they perceive it. Indeed, panel (c) of table 2 shows that the average actual inequality amounts to about 0.4, while the average ethical wage inequality equals 0.285 . The table further shows that only a tiny fraction of individuals favors absolute equality of wages (i.e. $G^{j}=0$ ), and that not one individual perceives not wage inequality at all.

Table 2, panel (c)

The top panel of figure 2 shows the joint distribution of the two subjective inequality measures. Clearly, most individuals desire a lower level of wage inequality than what they actually perceive to exist, as most individuals happen to lie below the $45^{\circ}$ line. The figure thus immediately shows that people hold not only widely different beliefs about what is judge as a fair distribution of wages across occupations, they in fact also have markedly different perceptions of reality. Further, for any given perception of wage inequality, there is still much variation across normative beliefs, and vice versa.

Figure 2

Panel (c) of table 2 shows that the average demand for redistribution equals about 0.3 , which implies that the average individual would like to decrease inequality in occupational wages by about a third, relative to what he perceives to prevail in reality. As a consequence, the bottom panel of figure 2 shows that most people - more than $96 \%$ actually - have a positive and substantial demand for redistribution, i.e. most people would favor a more equal distribution of wages. ${ }^{22}$ Also note that only a tiny fraction of all individuals would either like to eliminate all existing wage inequalities or no change in the wage distribution at all.

\subsection{Interpretation in Terms of Desired Redistribution}

An alternative and somewhat different interpretation of redistribution measure is directly based on individuals' absolute wage estimates and focuses on the underlying transfer payments that drive the observed difference in the two subjective Gini coefficients. This line of argument has been proposed by, inter alia, Blackburn (1989) and Koolman and van Doorslaer (2004). In the

\footnotetext{
${ }^{22}$ Figure 2 also shows that, perhaps somewhat surprisingly, there are some individuals for whom the just wage inequality is higher than the perceived inequality, resulting in a negative demand for redistribution. Further scrutiny of these 39 observations though shows that the reason for their negative demand for redistribution is not that they want to redistribute from the bottom to the top. What actually happens here is that these individuals want to increase not only the wage of the top group, but also the wage of the top group (and the desired increase of the top group is higher than the desired increase of the bottom group).
} 
present case this can easily be illustrated as the only transfers possible are from the bottom to the top group, or vice versa. Further, these transfer payments can easily be computed from the data for each individual. I first compute the absolute desired wage changes of the bottom and the top groups as $\left(\bar{y}(i)_{\text {bottom }}^{j}-\bar{y}(i)_{\text {bottom }}^{a}\right)$ and $\left(\bar{y}(i)_{\text {top }}^{j}-\bar{y}(i)_{\text {top }}^{a}\right)$, respectively. However, because the two groups have very different weights, it makes more sense to look at desired changes weighted by the corresponding population weight:

$$
\begin{aligned}
& f_{\mathrm{bottom}} \cdot\left(\bar{y}(i)_{\mathrm{bottom}}^{j}-\bar{y}(i)_{\mathrm{bottom}}^{a}\right) \\
& \left(1-f_{\mathrm{bottom}}\right) \cdot\left(\bar{y}(i)_{\mathrm{top}}^{j}-\bar{y}(i)_{\mathrm{top}}^{a}\right),
\end{aligned}
$$

The sum over these two terms gives an estimate of the overall transfers involved in order to achieve individual $i$ 's desired reduction of inequality:

$$
f_{\text {bottom }}\left(\bar{y}(i)_{\text {bottom }}^{j}-\bar{y}(i)_{\text {bottom }}^{a}\right)+f_{\text {top }}\left(\bar{y}(i)_{\text {top }}^{j}-\bar{y}(i)_{\text {top }}^{a}\right)
$$

This term is zero only when any desired increase of the lower wages are exactly offset by a corresponding transfer from the top to the bottom group. Otherwise, this measure can either be positive or negative. Therefore, the measure may yield some insight into whether people are aware that increasing the wages at the bottom of the distribution is not for free.

Table 2 panel (d), Figure 3

Panel (d) of table 2 gives descriptive statistics for these measures, while figure 3 shows the full distribution of the three relative measures. On average, the mean wage of the low wage group is increased by about $830 \mathrm{CHF}$, while at the same time the mean wage of the high wage group is decreased by almost six thousand CHF. Taking the population weights into account and re-expressing the extent of redistribution in terms of the overall actual wage, one gets the result that the additional wage sum (about $8.7 \%$ of the overall actual wage sum) that would be needed to raise the wage of the low wage group is more than offset by the wage sum which is, so to say, freed up by decreasing the wages at the top (about $15.6 \%$ of the overall actual wage). Taken literally, these results imply that the implementation of the desired redistribution of the average individual would incur additional costs of about $4 \%$ of the overall wage sum.

\subsection{Additional Empirical Moments}

As individuals were asked to estimate wages for different occupations, typically more than one wage estimate per group is available, some additional empirical moments describing more specific features of individual evaluations of the wage distribution can therefore be computed. In what follows, let $y(i)^{w}$ denote individual $i$ 's vector estimate of occupational wages relating to either actual $(w=a)$ or just $(w=j)$ wages. I follow the suggestions of and borrow some of the labels used by Osberg and Smeeding (2006), who mainly rely on these extreme values of wage estimates in their empirical analysis. The first additional aspect relates to the comparison of highest to lowest wage estimates, for either the actual or the ethical occupational wage 
distribution. That is, let us first define the wage floor floor $(i)^{w}$ as the minimum of $y(i)^{w}$ and the wage ceiling ceiling $(i)^{w}$ as the maximum of $y(i)^{w}$, both relative to the average occupational wage estimate:

$$
\begin{aligned}
\text { floor }(i)^{w} & =\left(\frac{\min \left(y(i)^{w}\right)}{\bar{y}(i)^{w}}\right), \quad \text { and } \\
\operatorname{ceiling}(i)^{w} & =\left(\frac{\max \left(y(i)^{w}\right)}{\bar{y}(i)^{w}}\right)
\end{aligned}
$$

These two measures describe the lower and the upper bound individuals place on the actual and the desired wage distribution, respectively. The second additional feature relates to the desired equalization of wages, which can occur by either increasing the wages at the bottom or by reducing the wages at the top of the distribution. This is easily captured by the ratio of ethical to actual floor and the ratio of ethical to actual ceiling, respectively:

$$
\begin{aligned}
\text { level-up }(i) & =\left(\frac{\text { floor }(i)^{j}}{\text { floor }(i)^{a}}\right), \quad \text { and } \\
\text { level-down }(i) & =\left(\frac{\operatorname{ceiling}(i)^{j}}{\operatorname{ceiling}(i)^{a}}\right)
\end{aligned}
$$

These two variables measure individuals' desired changes at the very bottom and top of the occupational wage distribution, respectively. Panel (e) of table 2 shows descriptive statistics for all four additional statistics.

Table 2, panel (e)

For example, individuals perceive the actual wage floor to amount to about $39 \%$ of the average actual wage. On the other hand, they think that the highest wage is about 4.7 times their average wage estimate (i.e. yielding a ratio of highest to lowest wage of about 12). Again, individuals' perceptions differ considerably from what they judge to be appropriate. The ethical floor evaluates to about $54 \%$ of the average wage estimate and the ethical wage ceiling is 3.6 times the average wage estimate, therefore yielding a ratio of about 6.5 - almost half the perceived spread in wages only. On average, individuals would like to increase the wage floor by almost $47 \%$, while they would like to decrease the wage ceiling by about $27 \%(=1 / 0.785)$.

\subsection{The Anatomy of the Demand for Redistribution}

Up to now, the data have clearly shown that most people do favor some reduction in wage inequality and thus most people have a positive demand for redistribution. It is not clear, however, whether the demand for redistribution is primarily driven differences as regards the perceived wage inequality or by differences with respect to the desired level of wage inequality, or eventually both.

Figure 4

Figure 4 shows the relation between the demand for wage redistribution and the two subjective gini coefficients. Interestingly, there is almost no correlation $(\hat{\rho}=0.0677)$ between the 
perception of the actual wage distribution and the demand for redistribution. On the other hand, there is a very clear negative correlation $(\hat{\rho}=-0.6302)$ between the evaluation of the desired wage inequality and the demand for redistribution.

\section{Figure 5}

Analogously, figure 5 shows scatterplots for some additional moments. The two figures at the left show the joint distribution of the actual and ethical wage floor and the actual and ethical wage ceiling, respectively. There is a clear positive correlation in both cases. The two figures in the middle plots the wage ceiling versus the wage floor, both for perceived and desired wages. Here, there's a clear negative correlation in the case of both perceived and desired wages. That is, individuals who perceive a higher than average wage floor tend to perceive a lower than average wage ceiling, conditional on average wage estimates. Finally, the two figures at the right show the correlation between the desire to level up the bottom wages and the perceived wage floor (top figure) and the correlation between the desire to level down the top wages and the ethical wage ceiling, respectively. Clearly, a low perceived wage floor tends to be associated with a desired wage change of wages at the bottom of the distribution, which is correspondingly higher. Similarly, the desired to decrease top wages is the lower, the higher the ethical wage ceiling.

Figure 6

Second, it may also be interesting to know whether the wish for redistribution is driven by desired changes of the lower or the upper tail of the wage distribution. Figure 6 therefore shows some simple scatterplots of the four moments defined in the preceding section versus the demand for redistribution. It is obvious that a higher ethical floor (ceiling) goes hand in hand with a higher (lower) demand for redistribution. On the other hand, the higher the desired leveling up of the bottom wages, the higher the demand for redistribution (and vice versa with respect to the leveling down of the wages at the very top).

In order to describe the overall pattern of associations between the different measures more succinctly, I run a series of simple regression models of the following basic form:

$$
\begin{aligned}
I_{i} & =\alpha+m_{i} \beta+\epsilon_{i}, \quad \text { and } \\
R_{i} & =\alpha+m_{i} \beta+\epsilon_{i},
\end{aligned}
$$

where $I_{i}$ and $R_{i}$ correspond, respectively, to the subjective inequality indices and the demand for redistribution, and $m_{i}$ is a vector of variables describing various moments of the subjective wage distribution of individual $i$, either along the dimensions of perception-versus-belief or along the of top-versus-bottom dimension of the subjective wage distribution. These simple regression models allow me to look at the simultaneous correlations among the different measures. There is no need to put any assumptions on the error term $\epsilon$ at this point, because I 
use regression explicitly only as a descriptive tool describing the patterns in the data. ${ }^{23}$ The resulting estimates are given in table 3 . The dependent variable in the first two columns is the actual inequality; it is the ethical inequality index in the following two columns, and the demand for redistribution in the remaining four columns.

Table 3

Obviously, the left- and right-hand side variables in equation (20a) and (20b) are mechanically correlated, as the dependent variable is a function of the regressors. But because their relation is nonlinear, the corresponding parameters can nonetheless be estimated from the data. Although the results from table 3 should therefore not be interpreted literally. Nonetheless, they can potentially clarify the question of how the demand for redistribution comes about in the first place in the sense that they may be informative about the relevant mechanisms generating the observed differences in the demand for redistribution.

The first two columns show that actual inequality is associated with overall actual wage estimates, but also with the perceived wage floor and ceiling. It's also evident that most of the variation of the dependent variable can be accounted for by these three regressors (Rsquared of about $90 \%){ }^{24}$ The next two columns show analogous results using ethical wage inequality as dependent variable. As before, actual ethical wage estimates along with the ethical wage floor and ceiling explain most of the variation of the dependent variable. Interestingly, column (4) shows that neither perceived floor nor perceived ceiling have an impact on ethical inequality once the corresponding moments describing the ethical wage distribution have been taken into account. The dependent variable in the remaining four columns is the demand for redistribution. First, column (5) shows that the demand for redistribution is only weakly associated with moments describing the actual wage distribution - the model yields a low R-squared of less than $3 \%$. The corresponding moments from the ethical distribution, on the other hand, do explain a large fraction of the observed variation, as shown in column (6) (Rsquared increases to about 55\%). The second to last column shows that moments from the actual distribution have explanatory power, given that the ethical moments are already taken into account. This suggests that the demand for redistribution is shaped by both perceptions and normative beliefs. Moreover, both the bottom and the top of the wage distribution seem important. This is also born out by the model presented in the final column, which includes the level-up and level-down variable instead of wage floor and ceilings.

The results of table 3 suggest that the variation in the demand for redistribution is simultaneously driven by both the perception of how the distribution of wage actually looks like and by the desired distribution. Viewed from yet another angle, both the desire to level-up wages

\footnotetext{
${ }^{23}$ Note that I can run these regressions only because the dependent variable is not a perfectly linear function of any of these moments. However, the model should not include too many regressors so as to maintain some useful ceteris-paribus interpretation of the individual coefficients. Also note that the size of the coefficients is not very informative because of the mechanical relation between dependent and independent variables.

${ }^{24}$ Normally, one would of course not care too much about the R-squared. In the present context however, interest lies in the mechanical relations between the variables, and thus in this specific context the R-squared delivers useful information about the correlational structure of the data.
} 
at the bottom and to level-down wages at the top of the occupational wage distribution are driving the variation in the amount of redistribution between individuals.

\section{The Demand for Redistribution}

If attitudes really are associated with the amount of factual redistribution, then one would expect that individuals' inequality perceptions, their perceptions of the determinants of pay as well as their normative attitudes about distributive justice to play a role in explaining the observed variation in the demand for redistribution. ${ }^{25}$ I have therefore constructed four key variables which are meant to capture some of the key motives behind the demand for redistribution (see appendix A for details). The first two variables relate to the normative dimension, that is they focus on people's normative beliefs about what factors should determine pay and economic success. One of these variables measures the extent to which people think that needs should be important in determining an individual's pay. The other variable refers to whether a person thinks that effort and skills should determine pay. These two variables are meant to capture two of the most important concepts related to distributive justice, the principle of need and the equity principle (Konow, 2003). According to the need principle, resources should be allocated according to individual need, for example whether a person has to look after children. The equity principle, on the other hand, rests upon considerations of proportionality and responsibility. According to this principle, individuals should obtain a wage that is commensurate with the effort they exert or the responsibility they bear. ${ }^{26}$ The other two key regressors measure what individuals actually perceive to be important in determining pay. Individuals who belief that it is mainly factors outside their onw control (e.g. ascribed factors like gender or ethnicity) are important for ascending the income distribution are presumably more inclined in supporting redistribution. On the other hand, individuals who strongly belief that individual effort and skills (e.g. aquired factors like education) are important for why people differ in their incomes, are less prone to support income redistribution. As pointed out by Bénabou and Tirole (2006), this belief might be so strong that individuals might even judge an unfair reality as fair, in order that their perception of 'reality' does not conflict with their own beliefs. ${ }^{27}$

However, the standard economic view on redistribution postulates that the demand for redistribution is primarily linked to an individual's position in the income distribution (e.g. Meltzer and Richard, 1981), and that the poorer individuals will favor redistribution because they will gain disproportionately from redistribution, and vice versa for richer individuals.

\footnotetext{
${ }^{25}$ The recent survey by Fong et al. (2005) provides a good overview over the relevant lines of argument, and Kluegel and Smith (1981) discuss the same issue from a sociological point of view.

${ }^{26}$ See Roemer (1998) for the closely related concept of equality of opportunity. Shepelak and Alwin (1986) discuss related concepts from a sociological point of view.

${ }^{27}$ The most prominent example probably is the United States, where only a minority of people beliefs that luck determines income but a majority thinks that the poor are poor because they are lazy and don't work hard enough to get out of poverty (Alesina et al., 2001). However, this strongly contrasts with the fact that social mobility in the United States is not exceptionally high (e.g. Solon, 2002).
} 
We thus would expect personal income to be one of the key predictors for the demand for redistribution at the individual level. Income is at the same time the main confounding factor because it may correlate with individuals' perceptions and normative beliefs. Moreover, one would also expect that individuals at the very top of the actual income distribution would oppose any amount of redistribution. However, empirical studies consistently show that income per se is not a very strong predictor for the support for redistribution (e.g. Corneo and Grüner, 2002; Fong, 2001). One potential explanation for this finding is income mobility - or at least individuals' belief in income mobility - which might blur the relation between current income and the demand for redistribution, as argued by Bénabou and Ok (2001). The (belief in the) possibility of upward-mobility as well as the potential risk of downward-mobility might mitigate the relation between income and the demand for redistribution in such a way that one's expectations about future income at least in part determine his current support for redistributive measures (Alesina and La Ferrara, 2005). This mechanism may also explain that there is no uniform support for income redistribution even among the poor, who would immediately gain from such policies (Fong, 2006). On the other hand, the risk of downward mobility may lead even some rich individuals to support income redistribution as a way of insuring against such shocks (Piketty, 1995). I therefore also include a measure for past social mobility in the empirical analysis below.

On top, several authors have pointed out that well-being may not only depend on absolute level of income but also - or perhaps even more so - on one's relative income, i.e. on income relative to some reference point (e.g. Clark and Oswald, 1996; van Praag et al., 2003). A similar argument might apply to the demand for redistribution: Support for redistribution might be driven by the extent to which an individual thinks that her own pay is higher (lower) than what she thinks would be appropriate or legitimate (Corneo and Grüner, 2002). It could even be the case that the absolute level of income is irrelevant and that the relevant explanatory factor is the extent to which one is satisfied with her level of income. I therefore will also include a variable which measures satisfaction with one's own level of pay.

\subsection{Main Results}

In order to assess the importance of the different factors in explaining the demand for redistribution, I run several simple linear regression models of the following form:

$$
R_{i}=\alpha+\operatorname{beliefs}_{i} \gamma_{1}+\operatorname{sinterest~}_{i} \gamma_{2}+\operatorname{controls}_{i} \beta+\epsilon_{i}
$$

where $R_{i}$ again denotes the redistribution measure, and the two vectors beliefs $s_{i}$ and sinterest $_{i}$ refer to either the four variables describing beliefs and perceptions or the variables describing self-interested motives for redistribution. As the label suggests, controls ${ }_{i}$ is a vector of additional control variables. ${ }^{28}$ I thus try to control for as many potentially important factors

\footnotetext{
${ }^{28}$ The following variables are included as additional controls: Age in years (and it's square), education (highest attained level, in years), a female dummy, a foreign-born dummy, a dummy indicating residence in the german speaking part of Switzerland, living in an urban area, two dummy variables indicating unemployment and
} 
as possible in order to minimize biased estimation of the key parameters. By including age, gender and education (among others) as regressors, I hope to mitigate confounding by unobserved factors like, for example, risk aversion. $\alpha, \beta, \gamma_{1}$ and $\gamma_{2}$ are the corresponding vectors of parameters to be estimated, with $\gamma_{1}$ being of main interest.

Table 4

Results are given in table 4 . The model in column (1) shows the estimates from a regression of the demand for redistribution on individuals' perceptions and normative beliefs only. All four regressor have the expected sign, although not all of them achieve statistical significance. ${ }^{29}$ More importantly, the estimated effects are large in substantive terms. For example, an increase in the belief that effort should be important in determining pay of one standard deviation (which is about 0.45 , as shown in table D.1 in the appendix) leads to a hypothetical decrease in the demand for redistribution of -0.034 , or about $11 \%$ if evaluated at the mean of the dependent variable (which equals 0.304 ). The belief that needs should be important in determining pay has an effect of about equal size but opposite sign. A one standard deviation increase of this variable implies an increase in the demand for redistribution by about 0.03 (or about 25\%). Analogously, the relative effects of a one standard deviation of the perception that ascribed and acquired skills are important for determining pay are $4 \%$ and $6.6 \%$, respectively. The second column includes additional controls. This diminishes the estimated coefficients of interest somewhat, but it does not change the qualitative pattern of the results, implying that the correlation between the different sets of regressors is not very strong. However, the additional control variables do have additional explanatory power (the adjusted R-squared for the model in the first column is $6.5 \%$, and $12.2 \%$ for the model in the second column). The next two models additionally include self-interested motives for redistribution: They additionally include the log of personal income, the mobility index and the justice evaluation measures. Somewhat surprisingly perhaps, the two coefficients related to normative beliefs remain almost the same and they keep their statistical significance. This holds true even if controlling for both selfinterested motives and additional controls, as shown in column (4). Besides, and interesting on its own, self-interested motives also have the expected sign throughout. Personal income has a significant and large negative effect on the demand for redistribution. The model in column (4) yields a semi-elasticity the demand for redistribution with respect to income of about -0.04, so doubling an individual's income would imply a decrease in the demand for redistribution by more than 10 percent, if evaluated at the mean of the dependent variable. Nonethelsee, even the richest individuals in the sample still have a positive demand for redistribution. More surprising is the large and statistically significant effect running from the justice evaluation of coworkers' wage on the demand for redistribution. It is thus indeed the case that individuals who feel that they are not paid enough have a much higher demand for redistribution, even conditional on

nonemployment (employment is used as the reference category), a scale measuring the perception of conflicts, an occupational prestige scale and individuals' political self-assessement on a simple left-right scale. See appendix A for the exact definitions of these variables.

${ }^{29}$ However, testing one-sided hypotheses would probably be appropriate and would also yield a significant effect of the perception that ascribed skills are important in determining pay. 
their absolute level of income. The index of social mobility however turns out to have a very small effect only, both in economic and statistical terms. The last model additionally includes the interaction between log income and the justice evaluation. The interaction turns out to be negative, implying that the effect of income on the demand for redistribution is larger, the more one thinks that he and his coworkers are underpaid. Alternatively, the higher an individual's income, the less does she think that her coworkers are underpaid. Although this effect turns out to be large in size, it is estimated very imprecisely and is thus not statistically different from zero.

\subsection{Other Moments Describing Subjective Wage Data}

Table 5 presents additional results for subjective inequality measures other than the demand for redistribution. I simply re-estimate the model from equation (21), using alternative subjective inequality measures as dependent variables:

$$
m_{i}=\alpha+\operatorname{beliefs}_{i} \gamma_{1}+\operatorname{sinterest}_{i} \gamma_{2}+\operatorname{controls}_{i} \beta+\epsilon_{i}
$$

with $m_{i}$ referring to either one of the two subjective inequality indices or to some other moment describing individuals' perception or evaluation of the occupational wage distribution. In the first three columns of table 5, moments related to the perceived wage distribution are used as dependent variables. Measures describing analogous moments of the distribution of ethical wages are used in the following three columns.

\section{Table 5}

Starting with those moments describing the distribution of perceived wages, the main point noteworthy is that the only significant relate to the two variables which capture people's perceptions of what determines pay. However, they also turn out to be insignificant when modeling the perceived wage ceiling. The second point to note is that neither normative beliefs nor personal income are associated with perceived wage inequality. So it does not seem to be the case that individuals with high income have different perceptions than low-income individuals, for example. Neither appear normative beliefs to feedback to individuals' perceptions. The size of the effects turn out to be quite large again. An increase in the perception that acquired skills are important in determining pay of one standard deviation (about 0.6) decreases the perceived inequality index by somewhat less than 0.01. If evaluated at the mean of the dependent variable, this amounts to a relative decrease of about $2.5 \%$. Turning to moments describing the ethical distribution of wages next, we note that individuals' perceptions become insignificant in these models. In turn, individuals' beliefs now have statistically significant effects. Again, this holds only true for the Gini coefficient as well as for the lower bound on wages, but not for the ceiling with respect to ethical wages. Moreover, individuals' estimates of the wage ceiling, regarding the actual as well as the ethical distribution, appear much more idiosyncratic than their estimates of overall wage inequality or their estimates on lower wages. Further, the comparison between actual and ethical moments further shows that individuals' perceptions 
are more heterogeneous than their normative beliefs, conditional of course on the variables that are included in the regression models. For example, the R-squared for the regression modeling the actual inequality index is 0.096 , while the analogous regression with respect to ethical wage inequality yields a value of 0.149 .

\subsection{Sensitivity Checks}

Table 6 shows parameter estimates for exactly the same regression models of table 4 , but using the difference between actual and ethical inequality index as dependent variable. That is, the dependent variable in table 6 is $\Delta G \equiv G^{a}-G^{j}$. Comparing the results of table 4 and of table 6 shows that the two variables yield very similar results: All estimates of the different specifications have the same sign, and so the qualitative pattern of the results is exactly the same. However, the corresponding parameter estimates turn out to be larger for the most part while standard errors go down at the same time, resulting in more precise estimates for most, but not all, regressors. Overall, the results are certainly not driven by the choice of functional form of the dependent variable.

\section{Table 6}

The dependent variable in table 7 is a 'standard' survey item, one which is normally used in similar empirical studies. Specifically, individuals were asked the following question: "Do you agree or disagree: Income differences in Switzerland are too high". They could choose whether they (strongly) agree, neither agree nor disagree, (strongly) disagree, or couldn't choose among the set of given possibilities. This measure is used as the dependent variable in table 7 . The estimates of table 7 look surprisingly similar as the ones presented in table 4 before. Again, almost all coefficients have the same sign as before.

\section{Table 7}

Additional sensitivity checks are provided in the appendix to this paper: Appendix C.1 shows some simple checks with respect to missing data and to potential sample selection and appendix C. 2 shows that the results are not sensitive to the choice of $f_{\text {bottom }}$, the population share of the bottom group. Results turn out to be robust with respect to both dimensions.

\section{$6 \quad$ Linking Subjective Beliefs to Outcomes}

In the final part of the analysis, I provide some indirect evidence on the hypothesized link between individuals' beliefs and norms about inequality and political outcomes, i.e. the actual amount of redistribution in the end. As I am using individual-level data for one country only, I can not directly relate individuals' beliefs to the relevant outcome which is observed at the aggregate level only. Nonetheless, I can provide some indirect evidence by looking at the linkages assumed to exist at the individual level: Given that redistribution is an outcome of a political process, studying whether individuals' propensity to support the welfare state as well as their stated party identification is associated with their subjective beliefs about distributive 
justice and redistribution may be informative about this link, even if such evidence is only indirect.

\subsection{Support for Redistribution by the State}

I start with the support for redistribution by the state, which may also be thought of as support for the welfare state more generally. I use a very simple measure, taken directly from the survey, which ranges from 1 to 5 (see appendix A again for the exact wording of the item). I then regress this measure on either the demand for redistribution or some other subjective inequality measure, along with some additional control variables:

$$
\operatorname{support}_{i}=\alpha+m_{i} \zeta+\text { interest }_{i} \gamma_{1}+\operatorname{beliefs}_{i} \gamma_{2}+\operatorname{controls}_{i} \beta+\epsilon_{i}
$$

where $m_{i}$ denotes either the demand for redistribution or a measure of subjective wage inequality, and the three vectors of control variables are exactly the same as before.

Table 8

Table 8 shows the results. The key regressor in the first three columns is the demand for redistribution. The demand for redistribution has a positive and statistically significant effect on the support for the welfare state in all models, whether individuals' beliefs or selfinterest motives are controlled for or not. As before, the estimated effect turns out to be large: Increasing the demand for redistribution by 0.198 (which corresponds to the standard deviation of the regressor) yields a predicted increase in the dependent variable of about 0.25 (which is about a fourth of the standard deviation of the dependent variable). Evaluated at the mean of the dependent variable, this results in a relative effect of about $8 \%(=100 \%[(0.198$. 1.277)/3.186]). Controlling simultaneously for individuals' beliefs and self-interested motives for demanding redistribution does not change the estimated coefficient by much (columns 2 and 3 ).

In the remaining three columns of table 8 , the two subjective inequality measures are included as key regressors. Again, both variables turn out to have large and significant effect on individuals' support for redistribution by the state. Here also, controlling for additional variables does not make much of a difference, and I therefore focus on the results in the sixth and last column. As before, both point estimates imply quite large effects. First, increasing the measure for actual inequality by about 0.4 leads to a predicted increase in the the support for redistribution by the state by 1.338 , which is more than one standard deviation of the dependent variable, and it implies an elasticity of more than one third (evaluated at the mean values). Similarly, an increase in the ethical inequality by 0.28 decreases the dependent variable by about 0.78 , implying an elasticity of about 0.25 .

Overall, the results clearly show that individuals who have a high demand for redistribution, or who perceive a high level of occupational wage inequality or think that only a low level of inequality is acceptable have a significantly higher propensity to be supportive of redistribution by the state. This in turn likely implies that these individuals are indeed more supportive of a 
system of taxation and transfer payments that explicitly aims at reducing the distribution in market wages.

\subsection{Party Identification}

Finally, I study the association between individuals' stated party preferences and the subjective inequality measures. To this end, I estimate some simple models of stated party preference, where the dependent variable is the stated preference for some political party and our main interest lies on the effect of the demand for redistribution, or alternatively some other moment of subjective evaluation of the wage distribution. ${ }^{30}$ It presumably is more plausible that beliefs and norms are determinants of party identification rather than the other way around. Thus, I will try assess empirically the link between (stated) party preference and the various measures describing different aspects of both the perceived and desired wage distribution. To keep things as simple as possible, I simply run a series of linear probability models of the form:

$$
\mathbb{1}\left(\operatorname{Party}_{i}=j\right)=\alpha+m_{i} \zeta+\operatorname{beliefs}_{i} \gamma_{1}+\operatorname{sinterest}_{i} \gamma_{2}+\operatorname{controls}_{i} \beta+\epsilon_{i}, \quad \forall \quad j=1, \ldots, 5
$$

The dependent variable is thus a dichotomous variable, indicating whether an individual identifies with party $j$. Stated party preference is thus mapped on five different binary variables, each indicating preference for one of the five political parties $j=1, \ldots, 5$, and therefore five different regression models are estimated. As before, $m_{i}$ denotes the inclusion of either the demand for redistribution or the two subjective inequality measures as key regressor(s), and beliefs $_{i}$, sinterest $i$ and controls $_{i}$ are the same sets of control variables as in the models shown before. The parameter of main interest is $\zeta$, capturing the effect of the subjective inequality measure on the stated party preference. ${ }^{31}$ However, the preceding section has shown the the various moments describing subjective evaluations of the wage distribution are clearly correlated with at least some of the control variables. As before, I therefore run the regressions on a restricted set of control variables also.

\section{Tables 9}

The main results are given in table 9. The top panel shows results using the restricted set of control variables, while the bottom panel includes the full set of regressors. ${ }^{32}$ First note that the difference in the estimated coefficients between the top and the bottom panel

\footnotetext{
${ }^{30}$ I only consider the five largest, with respect to actual voting shares, parties. These are the liberal-democratic party (FDP, "Freisinnig Demokratische Partei"), the christian democrats (CVP, "Christlichdemokratische Volkspartei"), the right-of-center conservative Swiss People's Party (SVP, "Schweizerische Volkspartei"), the social-democratic party (SPS, "Sozialdemokratische Partei der Schweiz"), and the left of center green party (GPS, "Grüne Partei der Schweiz"). The Swiss Federal Council, the executive council at the national level, consists of members of the first four parties mentioned.

${ }^{31}$ I also estimated a model in which the dependent variable is an indicator taking on the value one, if no party preference at all has been stated. In this case, no statistical effect whatsoever is found and thus I do not report these results here.

${ }^{32}$ Additionally, table D.2 in the appendix shows analogous estimates when using only those observations who stated any party preference at all. Results stay qualitatively the same when using this restricted set of observations.
} 
is as expected, in that in the models with the full set of control variables a significant part of the effect of $R_{i}\left(G_{i}^{w}\right)$ on party preference is absorbed by the controls. More importantly, all point estimates have the expected sign. The demand for redistribution has a negative effect on the probability of stating preference over the liberal party (FDP), but a positive effect on stating preference for one of the two left of center parties (SPS, GPS). Interestingly, the amount of redistribution desired also has a positive effect on stating preference for the right-of-center Swiss People's Party (SVP) and, more surprisingly, the effect is essentially the same as the effect for stating preference for the left. However, this effect also corresponds with what is known about voter turnout of the different parties in Switzerland. It is only in the case of the Christian-Democratic party that there is no effect at all (i.e. the point estimate is essentially zero). The size of the estimated effects turn out to be quite large. For example, a hypothetical increase in the demand for redistribution by one sample standard deviation (which is equal to about 0.2 ) would lower the probability of being in favor of the FDP by about $6.5 \%$ $(=-0.327 \cdot 0.2 \cdot 100 \%)$. Taking additionally the mean probability of the dependent variable into account and re-expressing the effect as an elasticity, it appears even larger: Evaluated at the sample mean of the demand for redistribution $(\simeq 0.3)$, the estimated elasticity of the probability of casting a vote in favor of the FDP with respect to the demand for redistribution equals about $-0.71(=(0.3 \cdot-0.327) / 0.139)$.

The same qualitative results emerge if the two subjective inequality measures are used as regressors - instead of the demand for redistribution. Again, there are no significant effects regarding the preference for the Christian-Democratic party whatsoever, but for all remaining parties at least one of the two subjective inequality measures has an effect which is statistically different from zero. First, identification with the liberal-democratic party is significantly shaped by both the perceived and the desired level of wage inequality. That is, individuals who perceive wage inequality to be low, and/or whose desired wage inequality is high tend to state preference for the FDP with a higher probability. In the case of the three remaining political parties (that is, SVP, SPS and GPS), the reverse pattern holds, i.e. people with a high level of perceived occupational wage inequality and/or a low level of ethical inequality tend to state preference for one of these three parties. Again, the bottom panel shows that the inclusion of more control variables does not change the relevant point estimates by much. Again, the effects turn out to be large. Considering the effects on the probability of being in favor of the FDP shows that an increase in the perceived wage inequality by one sample standard deviation $(\simeq 0.41)$ and an increase in the ethical wage inequality by one standard deviation $(\simeq 0.29)$ imply a decrease in the probability of being in favor of the FDP by about $13 \%$ and $4.5 \%$, respectively.

Overall, the data yield a consistent picture as regards the association between the demand for redistribution and party identification. Although the results do not fit a simple left-right pattern, these results are perfectly consistent with what is known about voter turnout of the different parties in Switzerland. Besides the rather obvious negative effect on voting for the liberal party and the positive effect on voting for social-democratic party, the results also coincide with what is known about the more special composition of the electorate of the Swiss 
People's Party (McGann and Kitschelt, 2005). Thus, the seemingly surprising result that a high demand for redistribution is associated with either stating preference for the left or the far-right is in line with what is known about the electorate of this party, which has attracted a substantial fraction of blue-collar workers (Oesch, 2008).

\section{Conclusions}

This paper presents a simple and intuitive conceptual framework which is suited for the empirical description of subjective evaluations of wage distributions and the demand for redistribution, and the framework is then applied using Swiss survey data from the ISSP. Because the conceptualization explicitly differentiates between individuals' perceptions and their normative beliefs about distributive justice, it naturally leads to a simple measure of the demand for redistribution as the discrepancy between an individual's perceived and desired distribution of wages. The empirical implementation of this framework also shows that the demand for redistribution is driven by both perceptions and normative beliefs, and on average is driven by the simultaneous wish to increase the lower part of the occupational wage distribution while at the same time

A first main results is that there is considerable support for redistribution and most individuals actually demand a positive amount of redistribution. In most cases, the demand for redistribution comes about as a combined effect of a desired increase of the wages at the bottom of the distribution and a decrease of the wages at the very top and thus reflects a discrepancy between the perceived and the desired distribution of wages. However, most individuals do accept large differences in wages at the same time, presumably reflecting the fact that people think that occupations differ in their educational requirements, responsibilities, and so forth. This suggests that absolute equality of wages is not the reference distribution towards which the actual distribution is compared to for most people. On the other hand, although there exists in fact a broad consensus that wages should differ between different occupations, there is also marked disagreement over how large these differences in wages should be.

Moreover, and well in line with previous evidence, the empirical analysis shows that selfinterested motives partially explain differences in the amount of redistribution desired. Specifically, individuals with higher wages demand less redistribution. Nonetheless, they still demand a positive amount of redistribution on average. Personal income by itself is thus in a way a remarkably weak predictor of the support of redistribution of wages, given its prominent role in the literature. Norms about distributive justice and beliefs as well as perceptions of how wages are determined in reality also explain some of the observed variation in redistribution. Again, this result is well in line with the existing empirical literature using non-experimental data. More importantly, I also find evidence on the hypothesized link between the demand for redistribution and political outcomes (which is thought to run through elections and voting). Indeed, subjective inequality measures turn out to have substantially large effects on both individuals' propensity to support redistribution by the state as well as on their party preferences. 
Overall, the framework proposed in this paper appears to be well suited for the empirical description of individuals' perceptions of wage inequality, what they judge as a fair distribution of wages, and their demand for redistribution. Applying the framework to data from other countries and other points in time may potentially yield interesting insights with respect to the understanding of country differences in factual inequality and the impact of redistributive policies. 


\section{References}

Abramitzky, R. (2008). The Limits of Equality: Insights from the Israeli Kibbutz. Quarterly Journal of Economics, 123(3), 1111-1159.

Alesina, A. and Angeletos, G.-M. (2005). Fairness and Redistribution. American Economic Review, 95(4), 960-980.

Alesina, A. and Fuchs-Schündeln, N. (2007). Good-Bye Lenin (or Not?): The Effect of Communism on People's Preferences. American Economic Review, 97(4), 1507-1528.

Alesina, A. and Giuliano, P. (2009). Preferences for Redistribution. NBER Working Paper No. 14825.

Alesina, A. and La Ferrara, E. (2005). Preferences for Redistribution in the Land of Opportunities. Journal of Public Economics, 89(5-6), 897-931.

Alesina, A., Glaeser, E., and Sacerdote, B. (2001). Why Doesn't the US Have a European-Style Welfare System? NBER Working Paper No. 8524.

Alesina, A., Di Tella, R., and MacCulloch, R. (2004). Inequality and happiness: are Europeans and Americans different? Journal of Public Economics, 88(9-10), 2009-2042.

Allan, J. and Scruggs, L. (2004). Political Partisanship and Welfare State Reform in Advanced Industrial Societies. American Journal of Political Science, 48(3), 496-512.

Alwin, D. (1987). Distributive Justice and Satisfaction with Material Well-Being. American Sociological Review, 52(1), 83-95.

Barr, N. (1992). Economic Theory and the Welfare State: A Survey and Interpretation. Journal of Economic Literature, 30(2), 741-803.

Beck, P., Dalton, R., Greene, S., and Huckfeldt, R. (2002). The Social Calculus of Voting: Interpersonal, Media, and Organizational Influences on Presidential Choices. American Political Science Review, 96(1), 57-73.

Bénabou, R. and Ok, E. A. (2001). Social Mobility and the Demand for Redistribution: The Poum Hypothesis. The Quarterly Journal of Economics, 116(2), 447-487.

Bénabou, R. and Tirole, J. (2006). Belief in a Just World and Redistributive Politics. The Quarterly Journal of Economics, 121(2), 699-746.

Blackburn, M. M. (1989). Interpreting the Magnitude of Changes in Measures of Income Inequality. Journal of Econometrics, 42, 21-25.

Borck, R. (2007). Voting, Inequality and Redistribution. Journal of Economic Surveys, 21(1), $90-109$.

Clark, A. (2003). Unemployment as a social norm: Psychological evidence from panel data. Journal of Labor Economics, 21(2), 323-351.

Clark, A. E. and Oswald, A. J. (1996). Satisfaction and Comparison Income. Journal of Public Economics, 61(3), 359-381.

Corneo, G. and Fong, C. (2008). What's the monetary value of distributive justice? Journal of Public Economics, 92(1-2), 289-308. 
Corneo, G. and Grüner, H. P. (2002). Individual Preferences for Political Redistribution. Journal of Public Economics, 83, 83-107.

Cowell, F. (2000). Measurement of Inequality. In A. Atkinson and F. Bourguignon, editors, Handbook of Income Distribution, volume 1, chapter 2, pages 87-166. Elsevier.

Di Tella, R. and MacCulloch, R. (2002). The determination of unemployment benefits. Journal of Labor Economics, 20(2), 404-434.

Di Tella, R. and MacCulloch, R. (2004). Unemployment benefits as a substitute for a conservative Central Banker. Review of Economics and Statistics, 86(4), 911-922.

Di Tella, R., Galiani, S., and Schargrodsky, E. (2007). The Formation of Beliefs: Evidence from the Allocation of Land Titles to Squatters. The Quarterly Journal of Economics, 122(1), 209-241.

Di Tella, R., Galiani, S., Schargrodsky, E., Field, S., and Drive, O. (2008). Reality versus Propaganda in the Formation of Beliefs about Privatization. NBER Working Paper No. 14483.

Feld, L. and Kirchgässner, G. (2000). Direct democracy, political culture, and the outcome of economic policy: a report on the Swiss experience. European Journal of Political Economy, 16(2), 287-306.

Feld, L. and Matsusaka, J. (2003). Budget referendums and government spending: evidence from Swiss cantons. Journal of Public Economics, 87(12), 2703-2724.

Fong, C. (2001). Social Preferences, Self-Interest and the Demand for Redistribution. Journal of Public Economics, 82, 225-246.

Fong, C. (2006). Prospective Mobility, Fairness, and the Demand for Redistribution. Working Paper, Carnegie Mellon University.

Fong, C. M., Bowles, S., and Gintis, H. (2005). Behavioural Motives for Income Redistribution. Australian Economic Review, 38(3), 285-297.

Ganzeboom, H. and Treiman, D. (1996). Internationally Comparable Measures of Occupational Status for the 1988 International Standard Classification of Occupations. Social Science Research, 25, 201-239.

Goren, P. (2005). Party Identification and Core Political Values. American Journal of Political Science, 49(4), 881-896.

ISSP (1999). Social Inequality III. ZA no. 3430.

Jasso, G. (1978). On the Justice of Earnings: A New Specification of the Justice Evaluation Function. The American Journal of Sociology, 83(6).

Jasso, G. (1980). A New Theory of Distributive Justice. American Sociological Review, 45(1), $3-32$.

Jasso, G. (1999). How Much Injustice is There in the World? Two New Justice Indexes. American Sociological Review, 64(1), 133-168.

Kakwani, N. and Podder, N. (1973). On the Estimation of Lorenz Curves from Grouped Observations. International Economic Review, 14(2), 278-92. 
Kelley, J. and Evans, M. (1993). The Legitimation of Inequality: Occupational Earnings in Nine Nations. The American Journal of Sociology, 99(1), 75-125.

Kluegel, J. R. and Smith, E. R. (1981). Beliefs about Stratification. Annual Review of Sociology, 7, 29-56.

Konow, J. (2003). Which Is the Fairest One of All? A Positive Analysis of Justice Theories. Journal of Economic Literature, 41(4), 1188-1239.

Koolman, X. and van Doorslaer, E. (2004). On the interpretation of a concentration index of inequality. Health Economics, 13(7), 649-656.

Korpi, W. and Palme, J. (1998). The paradox of redistribution and strategies of equality: Welfare State institutions, inequality, and poverty in the western countries. American Sociological Review, 63(5), 661-687.

Korpi, W. and Palme, J. (2003). New Politics and Class Politics in the Context of Austerity and Globalization: Welfare State Regress in 18 Countries, 1975-95. American Political Science Review, 97(03), 425-446.

McGann, A. and Kitschelt, H. (2005). The radical right in the Alps: Evolution of support for the Swiss SVP and Austrian FPO. Party Politics, 11(2), 147.

Meltzer, A. H. and Richard, S. F. (1981). A Rational Theory of the Size of Government. Journal of Political Economy, 89(5), 914-27.

OECD (2008). Growing Unequal? Income Distribution and Poverty in OECD Countries. Technical report, Organization for Economic Co-operation and Development.

Oesch, D. (2008). Explaining Workers' Support for Right-Wing Populist Parties in Western Europe: Evidence from Austria, Belgium, France, Norway, and Switzerland. International Political Science Review/ Revue internationale de science politique, 29(3), 349.

Osberg, L. and Smeeding, T. (2006). "Fair" Inequality? Attitudes toward Pay Differentials: The United States in Comparative Perspective. American Sociological Review, 71, 450-473.

Piketty, T. (1995). Social Mobility and Redistributive Politics. Quarterly Journal of Economics, 110(3), 551-584.

Roemer, J. E. (1998). Why the Poor Do Not Expropriate the Rich: An Old Argument in New Garb. Journal of Public Economics, 70(3), 399-424.

Sen, A. (2000). Social Justice and the Distribution of Income. In A. Atkinson and F. Bourguignon, editors, Handbook of Income Distribution, volume 1, chapter 1, pages 59-85. Elsevier Science.

Shepelak, N. J. and Alwin, D. F. (1986). Beliefs about Inequality and Perceptions of Distributive Justice. American Sociological Review, 51(1), 30-46.

Solon, G. (2002). Cross-Country Differences in Intergenerational Earnings Mobility. Journal of Economic Perspectives, 16(3), 59-66.

Stamm, H., Lamprecht, M., and Nef, R. (2003). Soziale Ungleichheit in der Schweiz. Seismo Verlag, Zürich. 
Stutzer, A. and Lalive, R. (2004). The role of social work norms in job searching and subjective well-being. Journal of the European Economic Association, 2(4), 696-719.

van Praag, B. M. S., Frijters, P., and Ferrer-i Carbonell, A. (2003). The Anatomy of Subjective Well-Being. Journal of Economic Behavior \& Organization, 51(1), 29-49.

Younts, C. W. and Mueller, C. W. (2001). Justice Processes: Specifying the Mediating Role of Perceptions of Distributive Justice. American Sociological Review, 66(1), 125-145. 
Table 1: Individuals' subjective estimates of occupational wages

\begin{tabular}{lcc}
\hline & Actual wage & Just wage \\
\hline (a) Bottom group: & & \\
Shop assistant & $2,998.82$ & $3,976.18$ \\
& $(577.63)$ & $(749.84)$ \\
Unskilled worker & $3,114.09$ & $3,860.95$ \\
& $(606.95)$ & $(710.44)$ \\
Skilled worker & $4,231.59$ & $4,988.29$ \\
& $(840.69)$ & $(941.73)$ \\
(b) Top group: & & \\
Doctor & $16,567.80$ & $13,044.56$ \\
& $(9,380.81)$ & $(7,304.43)$ \\
Lawyer & $18,086.77$ & $12,829.09$ \\
& $(10,715.83)$ & $(7,626.30)$ \\
Federal judge & $19,451.13$ & $15,386.43$ \\
Member of the Swiss Federal Council & $(9,031.87)$ & $(8,236.42)$ \\
& $(13,475.58$ & $18,389.69$ \\
Chairman & $24,874.78$ & $(10,798.76)$ \\
& $(17,091.40)$ & $(11,440.05)$ \\
Owner of a factory & $32,588.71$ & $24,215.12$ \\
& $(21,112.37)$ & $(16,898.07)$ \\
C) Respondent's occupation & & \\
Coworker & $6,304.21$ & $6,769.70$ \\
& $(5,675.92)$ & $(5,136.08)$ \\
\hline
\end{tabular}

Notes: The table shows average estimates of actual and just net monthly wages in Swiss francs (i.e. wages net of mandatory social security contributions, but before taxes and transfers). Standard deviations are given in parentheses. The number of observations varies somewhat between different cells because not all individuals gave estimates for all occupations. The maximum number of observations is 593, which corresponds to the sample used in the analysis also. See also appendix A for definitions and additional explanations. 
Table 2: Subjective inequality measures

\begin{tabular}{|c|c|c|}
\hline & Mean & $\begin{array}{l}\text { Standard } \\
\text { deviation }\end{array}$ \\
\hline \multicolumn{3}{|l|}{ (a) Actual (perceived) wage distribution } \\
\hline Overall wage & $7,829.463$ & $2,393.588$ \\
\hline Wage, bottom group & $3,449.972$ & 552.407 \\
\hline Wage, top group & $22,626.347$ & $10,076.362$ \\
\hline Population share, bottom group & 0.772 & - \\
\hline \multicolumn{3}{|l|}{ (b) Just (desired, ethical) wage distribution } \\
\hline Overall wage & $7,125.734$ & $2,027.020$ \\
\hline Wage, bottom group & $4,276.207$ & 680.431 \\
\hline Wage, top group & $16,753.367$ & $8,327.335$ \\
\hline Population share, bottom group & 0.772 & - \\
\hline \multicolumn{3}{|l|}{ (c) Subjective inequality and redistribution } \\
\hline Gini coefficient, actual wage distribution & 0.408 & 0.095 \\
\hline $\mathbb{1}($ Actual Gini $=0)$ & 0.000 & 0.000 \\
\hline Gini coefficient, desired wage distribution & 0.285 & 0.107 \\
\hline $\mathbb{1}($ Desired Gini $=0)$ & 0.002 & 0.041 \\
\hline Demand for redistribution & 0.305 & 0.198 \\
\hline $\mathbb{1}($ Demand $<0)$ & 0.030 & 0.172 \\
\hline $\mathbb{1}($ Demand $=0)$ & 0.005 & 0.071 \\
\hline $\mathbb{1}(0<$ Demand $<1)$ & 0.961 & 0.193 \\
\hline $\mathbb{1}($ Demand = 1) & 0.002 & 0.041 \\
\hline $\mathbb{1}($ Demand $>1)$ & 0.002 & 0.041 \\
\hline$\Delta$ Gini & 0.123 & 0.083 \\
\hline \multicolumn{3}{|l|}{ (d) Transfer payments } \\
\hline \multicolumn{3}{|l|}{ In absolute terms } \\
\hline Redistribution to the bottom & 637.523 & 390.663 \\
\hline Redistribution from the top & $-1,341.389$ & $1,561.470$ \\
\hline Overall & -703.866 & $1,524.850$ \\
\hline \multicolumn{3}{|l|}{ In relative terms } \\
\hline Redistribution to the bottom & 0.087 & 0.060 \\
\hline Redistribution from the top & -0.156 & 0.149 \\
\hline Overall & -0.069 & 0.158 \\
\hline \multicolumn{3}{|l|}{ (e) Additional moments } \\
\hline Perceived floor & 0.390 & 0.116 \\
\hline Ethical floor & 0.547 & 0.138 \\
\hline Perceived ceiling & 4.689 & 1.563 \\
\hline Ethical ceiling & 3.590 & 1.482 \\
\hline Level up & 1.471 & 0.443 \\
\hline Level down & 0.785 & 0.256 \\
\hline
\end{tabular}

Notes: All variables are defined in the main text. The numbers in panel (a), panel (b), and the first part of panel (d) refer to monthly wages in CHF (before taxes and transfers, but after the deduction of social security contributions; $1 \mathrm{CHF} \simeq 0.65 €$ ). All calculations are based on 593 observations. $\mathbb{1}(\cdot)$ denotes the indicator function. 


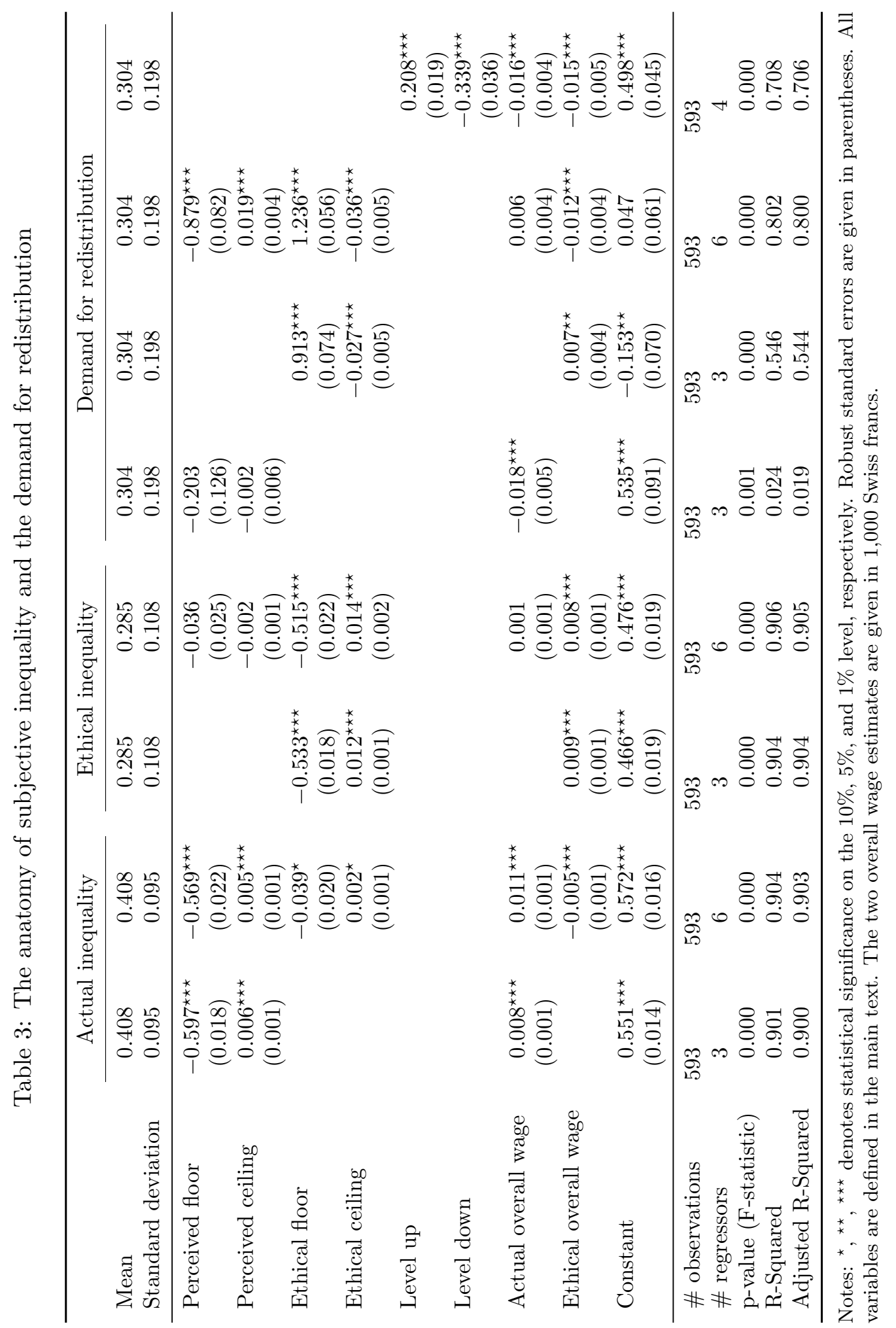




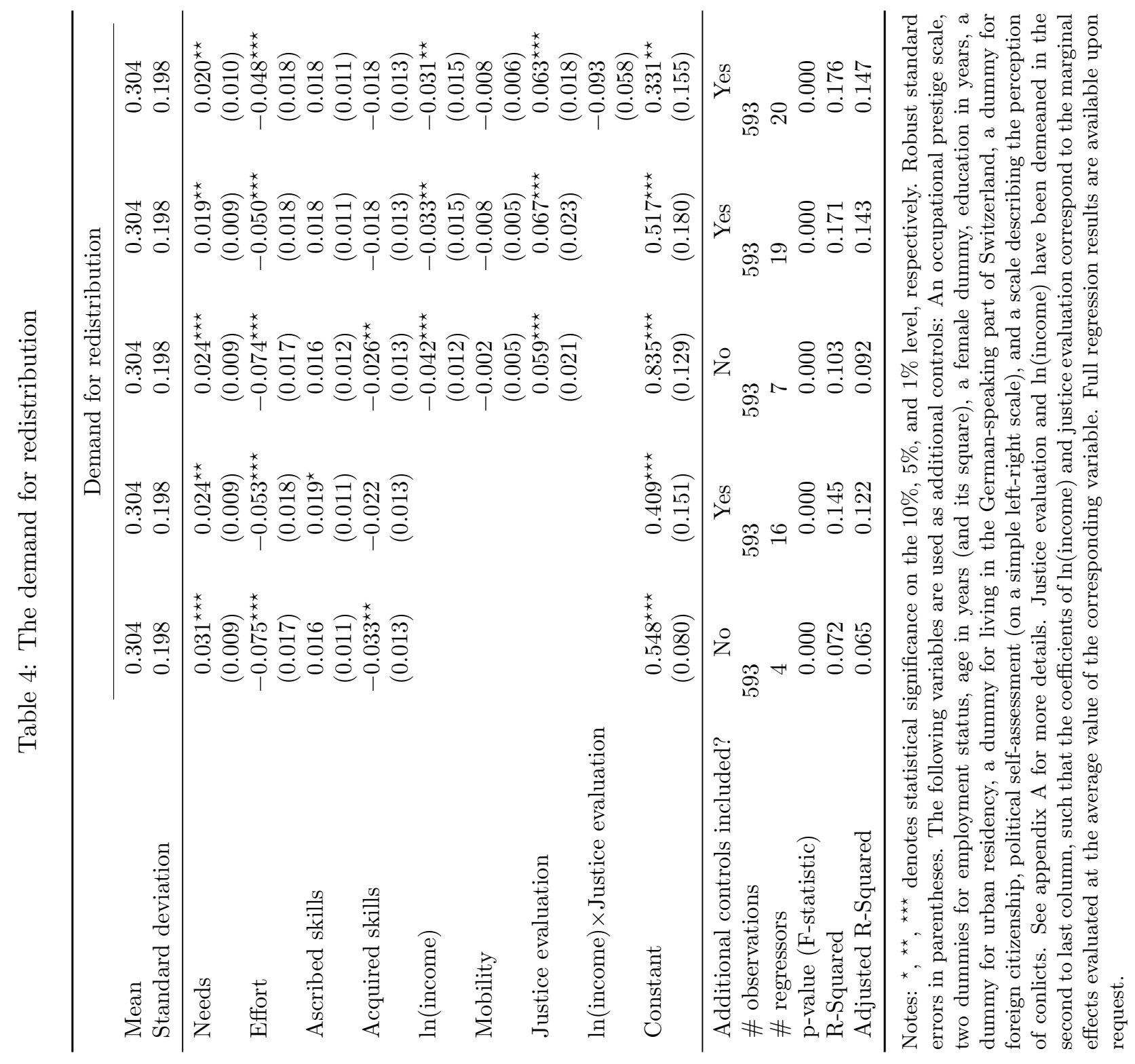




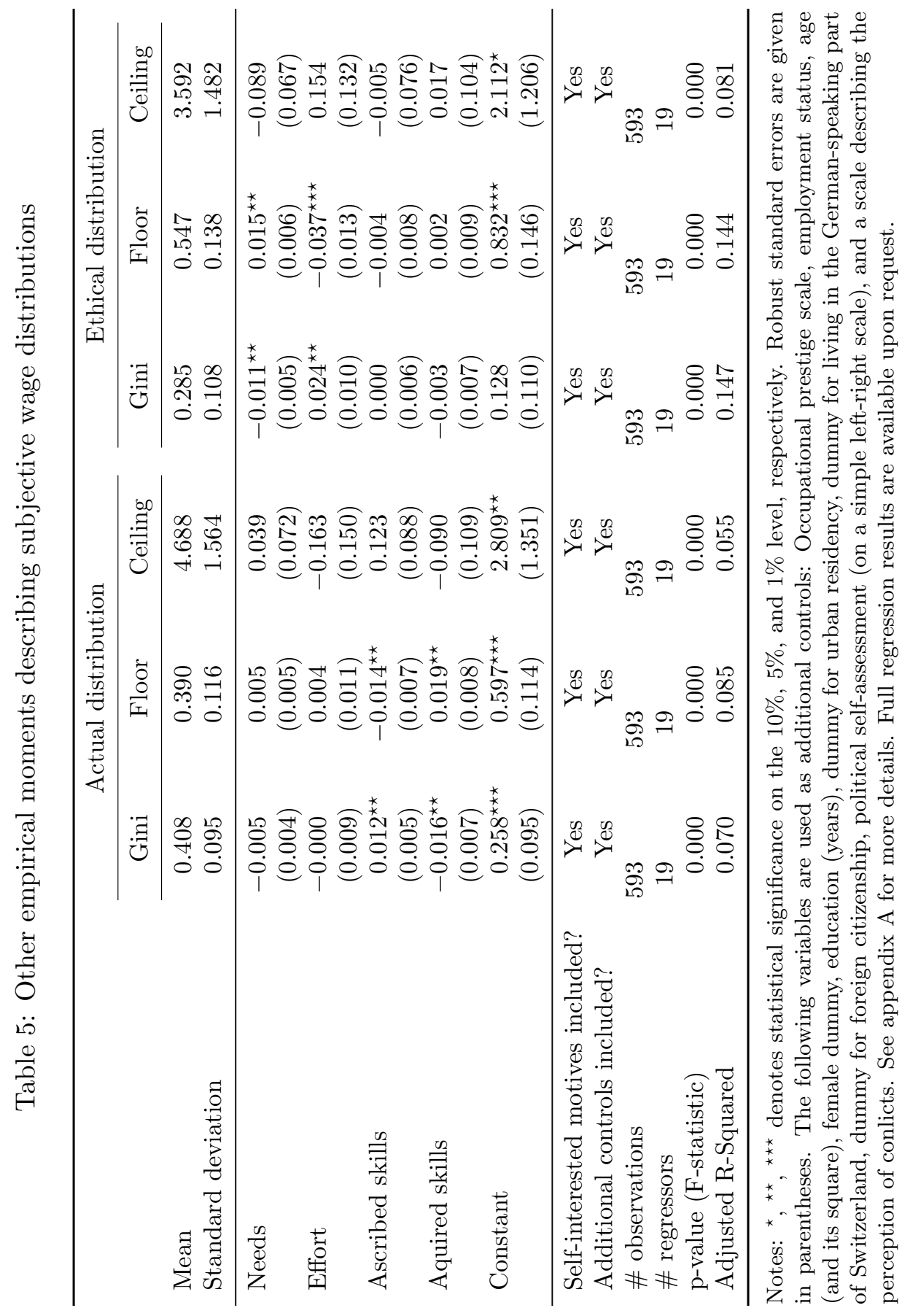




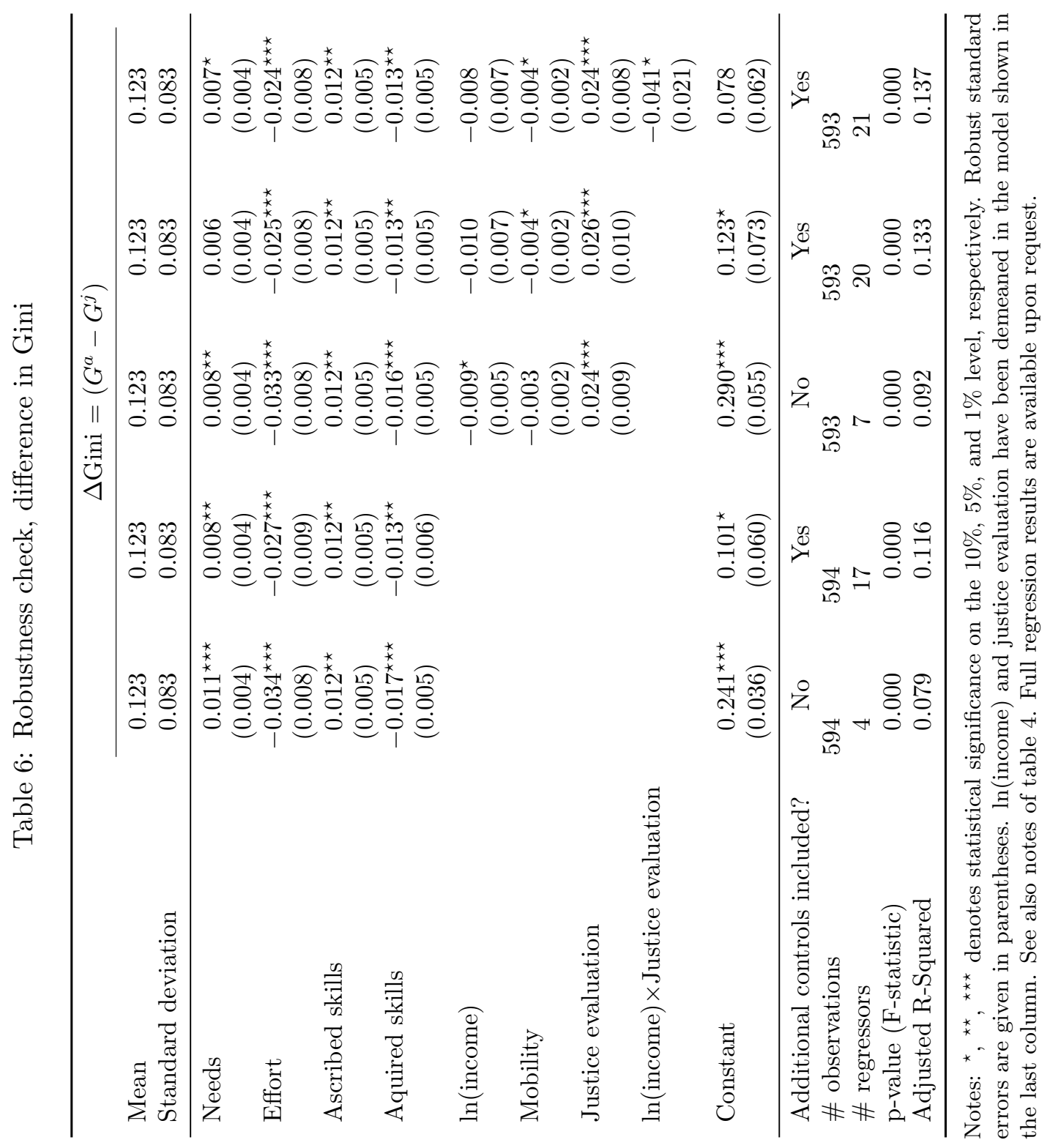




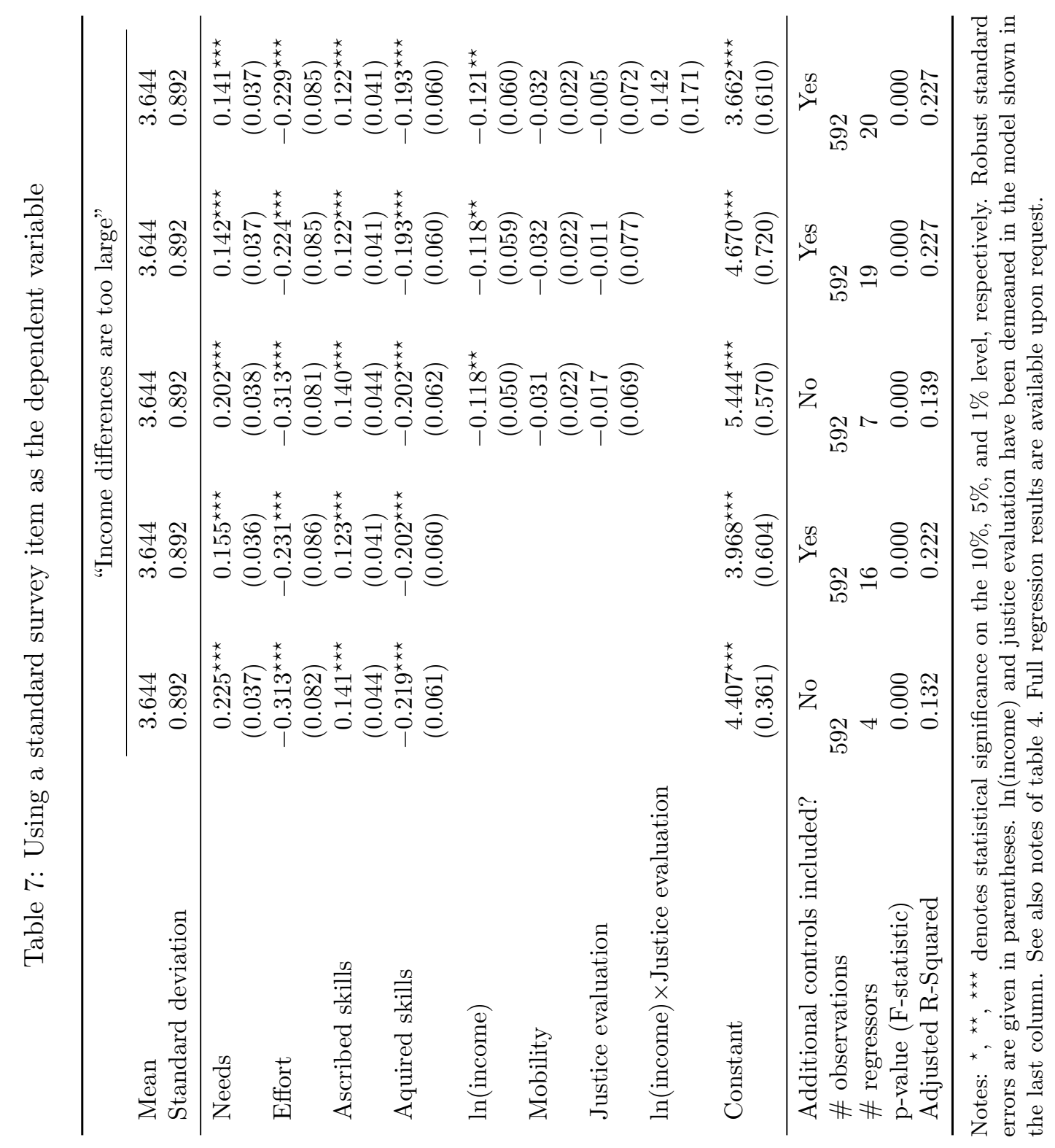




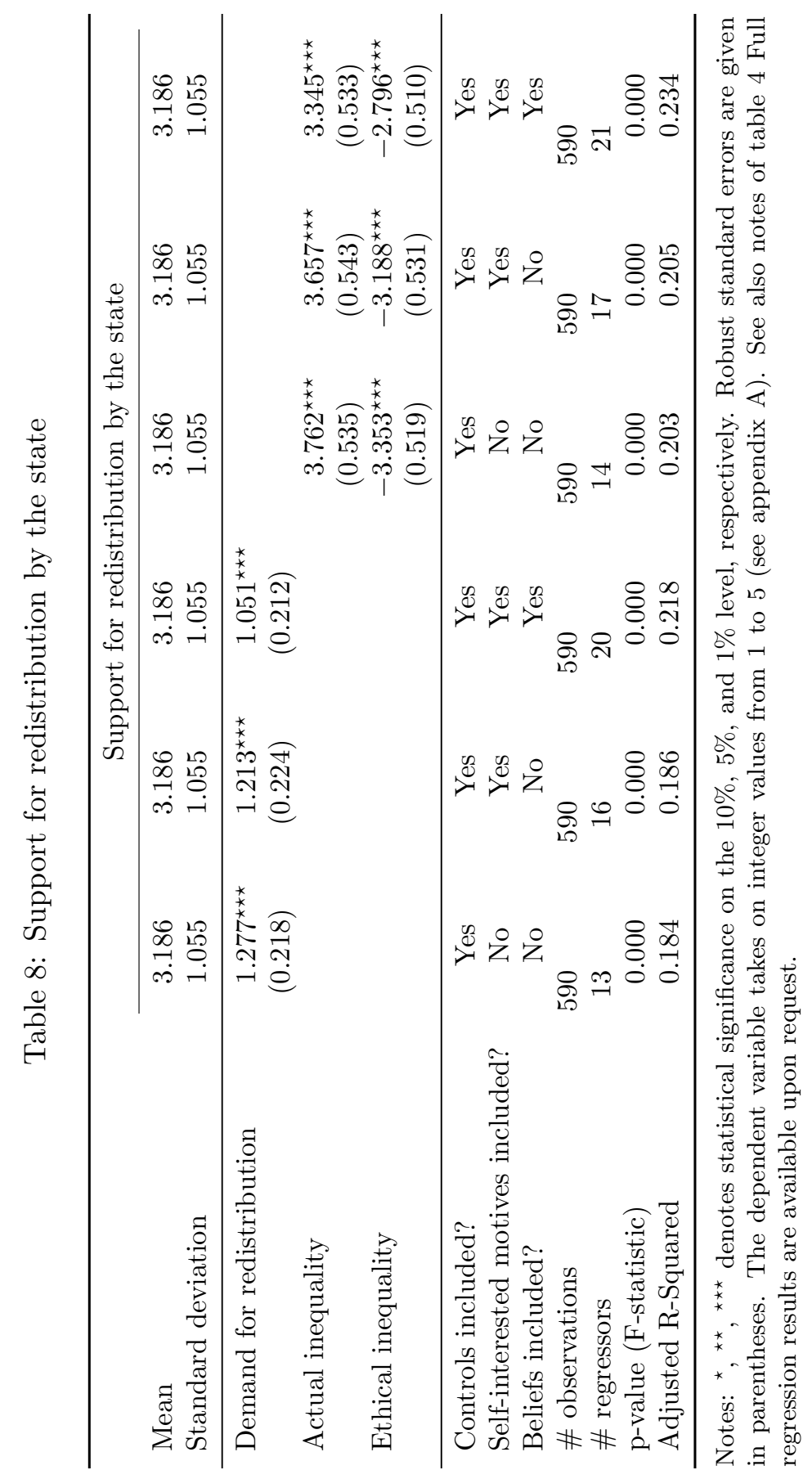




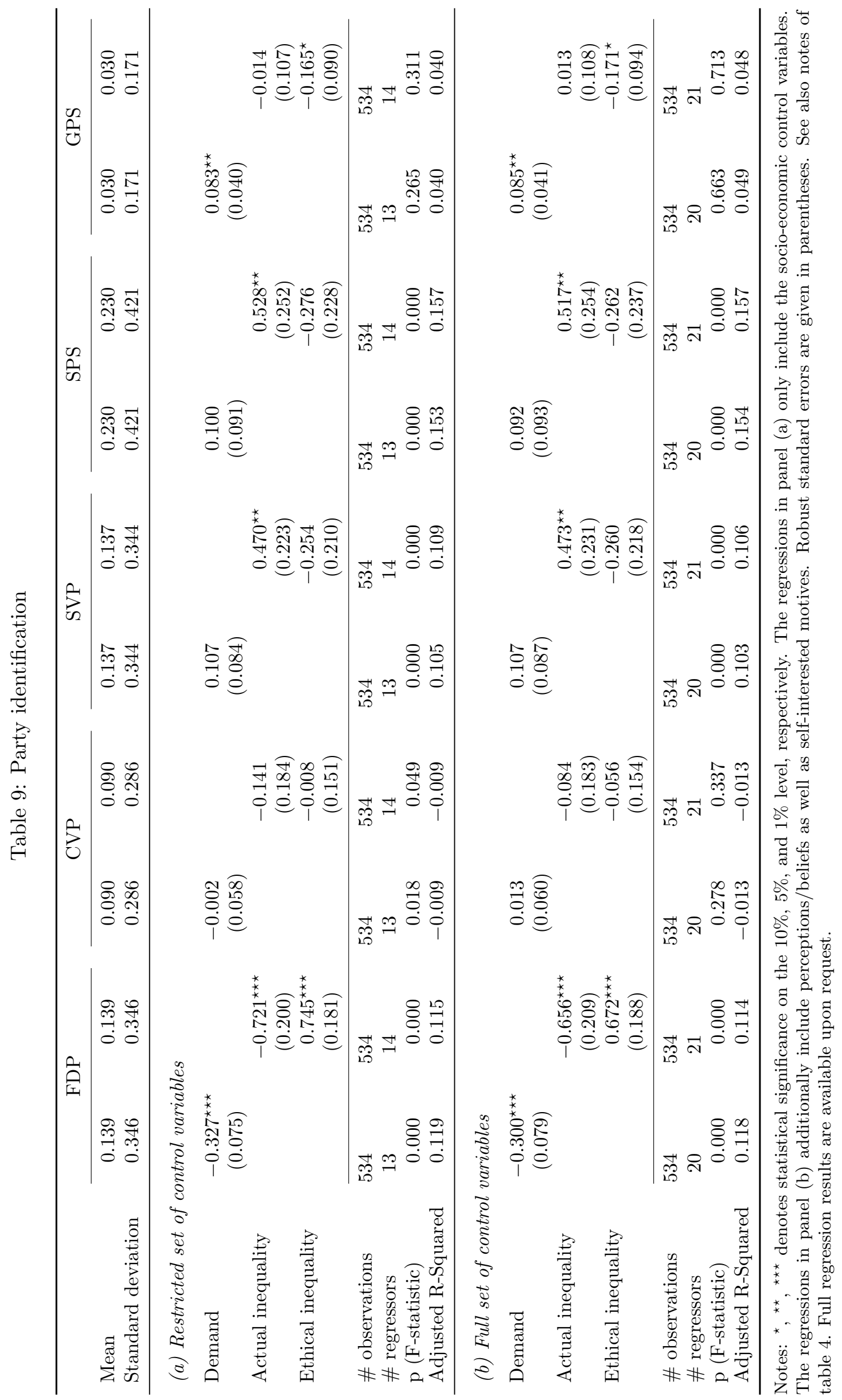


Figure 1: Estimates of occupational wages

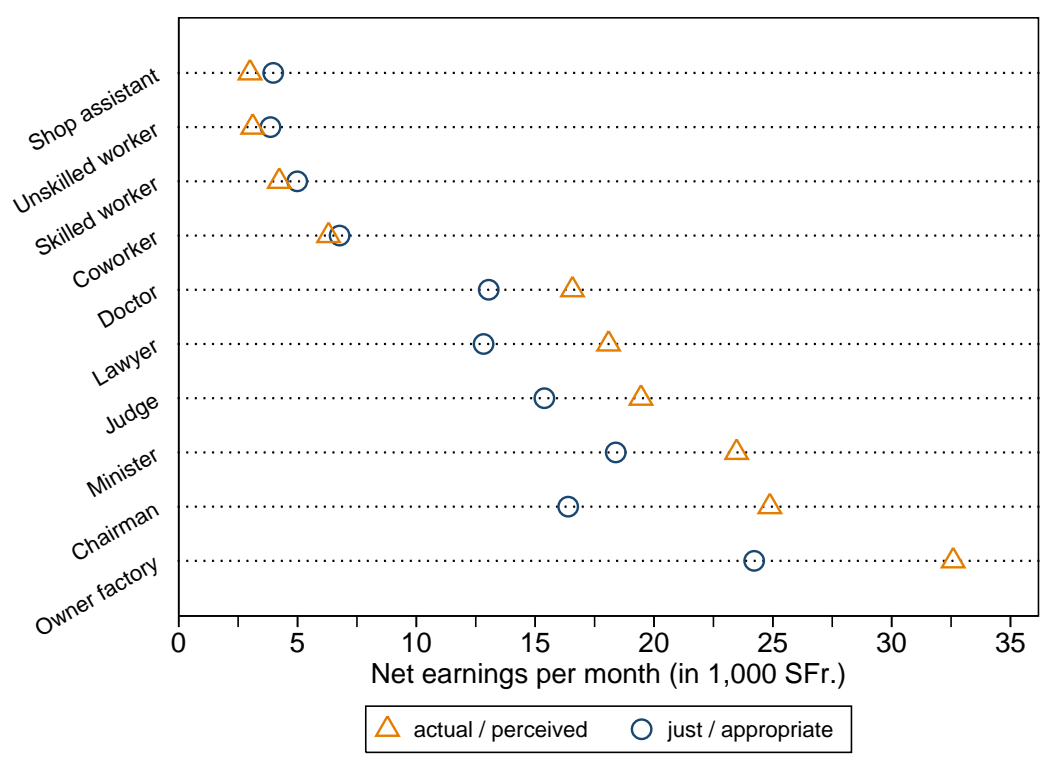

(a) Average wage estimates

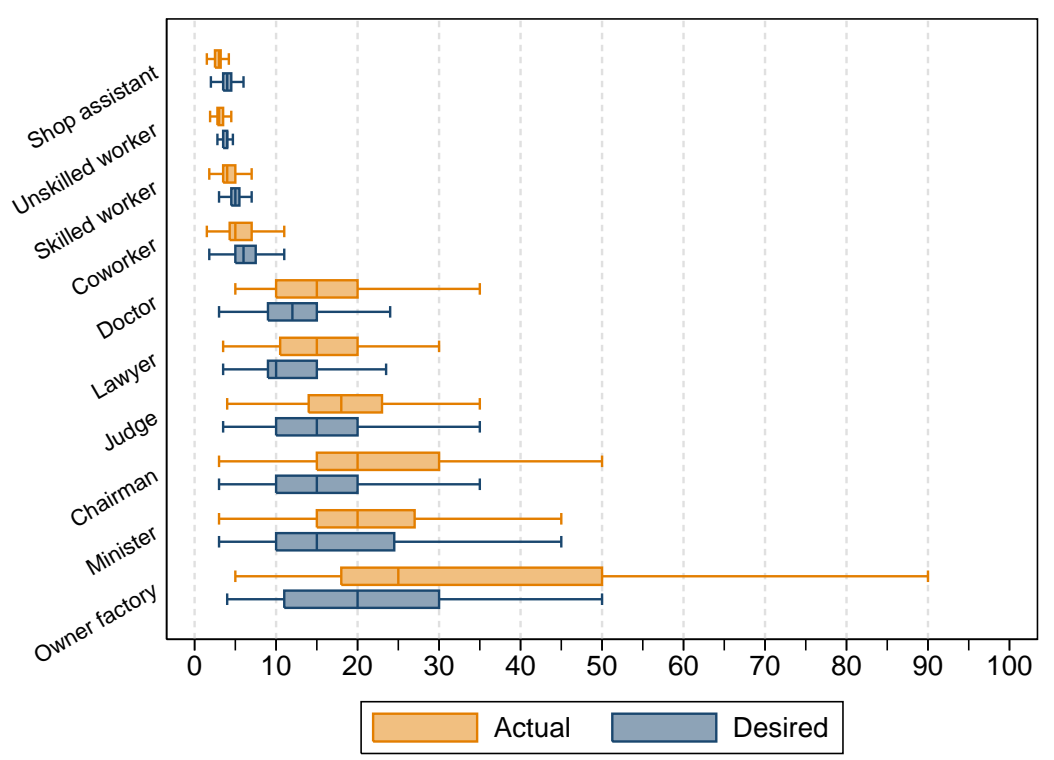

(b) Distribution of wage estimates

Notes: The hollow triangles correspond to the sample average of the actual (perceived) wage estimates. Analogously, the hollow circles denote averages of just (desired, ethical) wage wage estimates for the different occupations. Net earnings corresponds to earnings before taxes and transfer payments, but after the deduction of social security contributions. See notes of table 1 and appendix A for additional explanations. 
Figure 2: Subjective inequality measures and the demand for redistribution

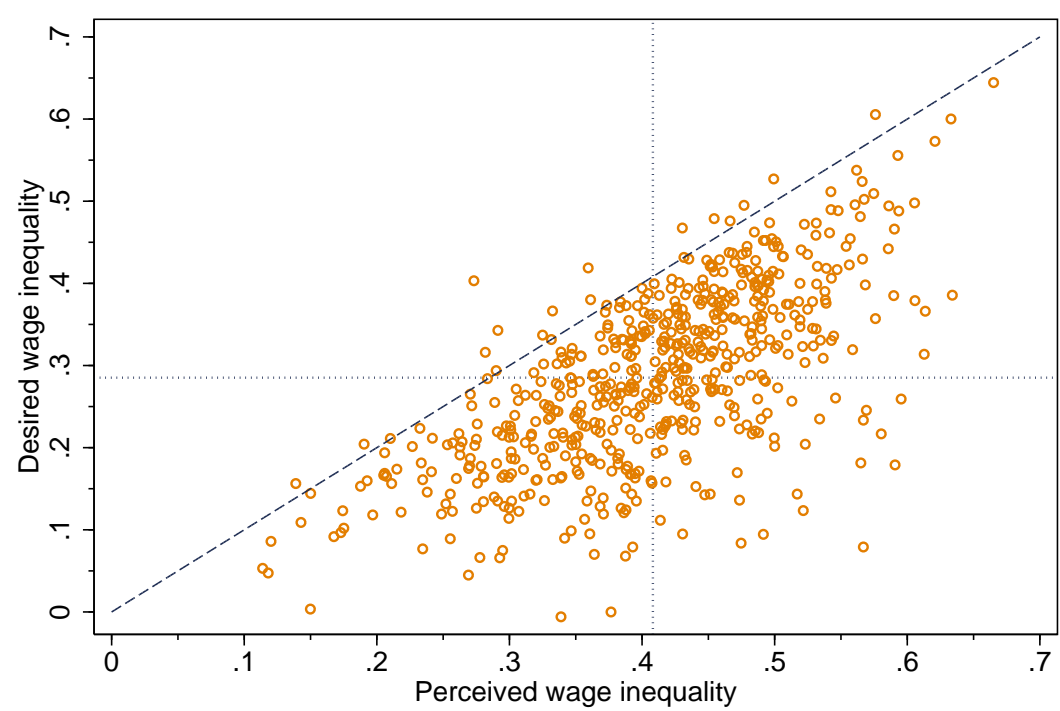

(a) Desired versus perceived occupational wage inequality

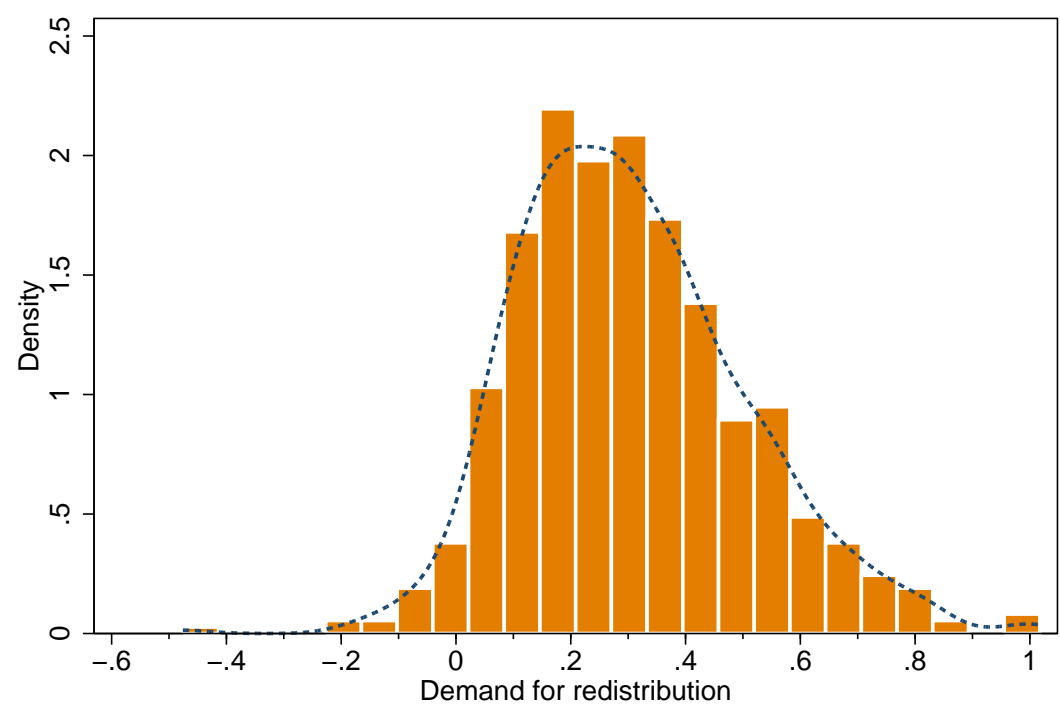

(b) The demand for redistribution

Notes: The figure in panel (a) shows the joint distribution of the perceived and the desired wage inequality. The dashed line corresponds to the $45^{\circ}$ line. The two dotted lines show the corresponding sample averages. The figure in panel (b) shows the distribution of the demand for redistribution. The dashed line shows the kernel density estimate using the Gaussian kernel and a bandwidth of about 0.048 . 
Figure 3: The demand for redistribution and the amount of transfer payments

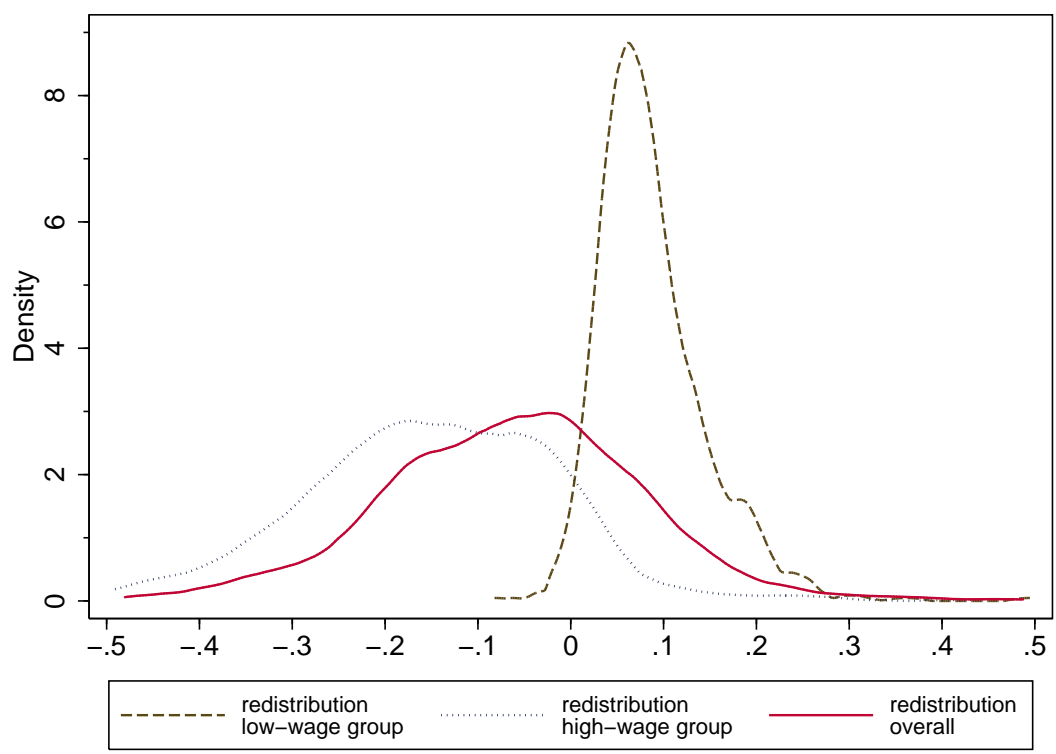

Notes: The figure shows the kernel density estimates of the three variables measuring the amount of transfer payments involved in order to achieve the desired amount of redistribution, relative to the overall actual wage estimate of a given individual. The dotted (dashed) line shows the transfer payments resulting from the desired change at the bottom (top) of the occupational wage distribution. The solid line corresponds to the sum of the former two, and thereby gives the total amount of transfer payments needed (freed up, respectively) in order to achieve a given desired amount of redistribution (i.e. a value of 0 signifies that the desired reduction in inequality can be achieved by solely redistributing from the top to the bottom group, without incurring any additional costs but also without freeing up any resources). 
Figure 4: Redistribution versus subjective wage inequality

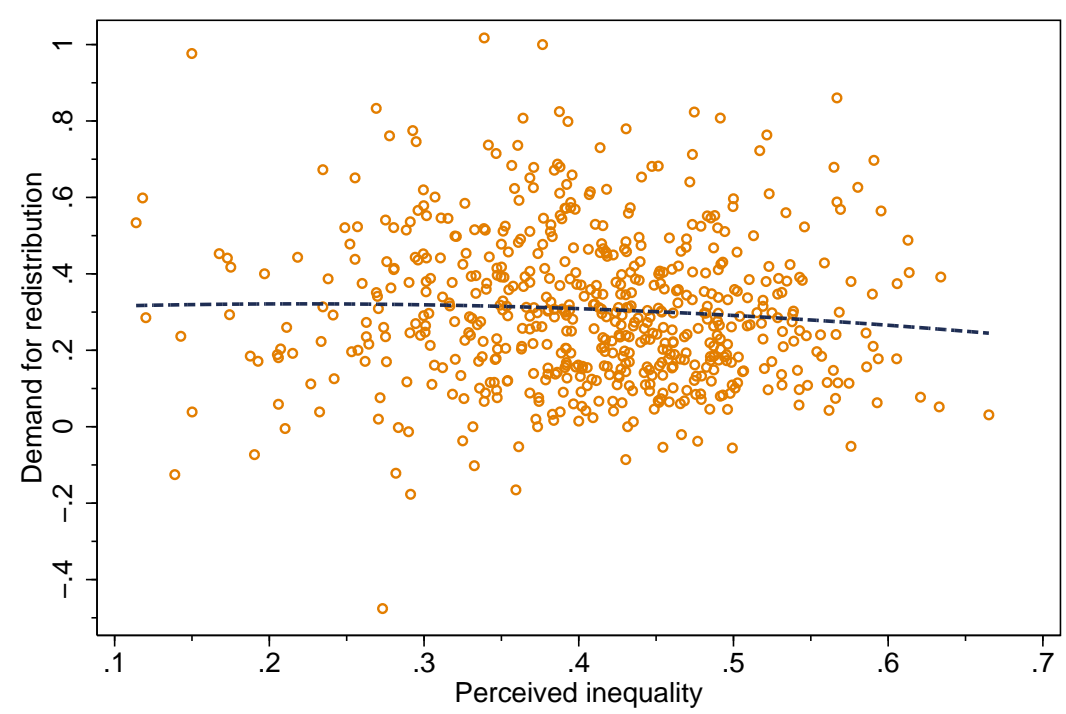

(a) Demand for redistribution versus perceived wage inequality

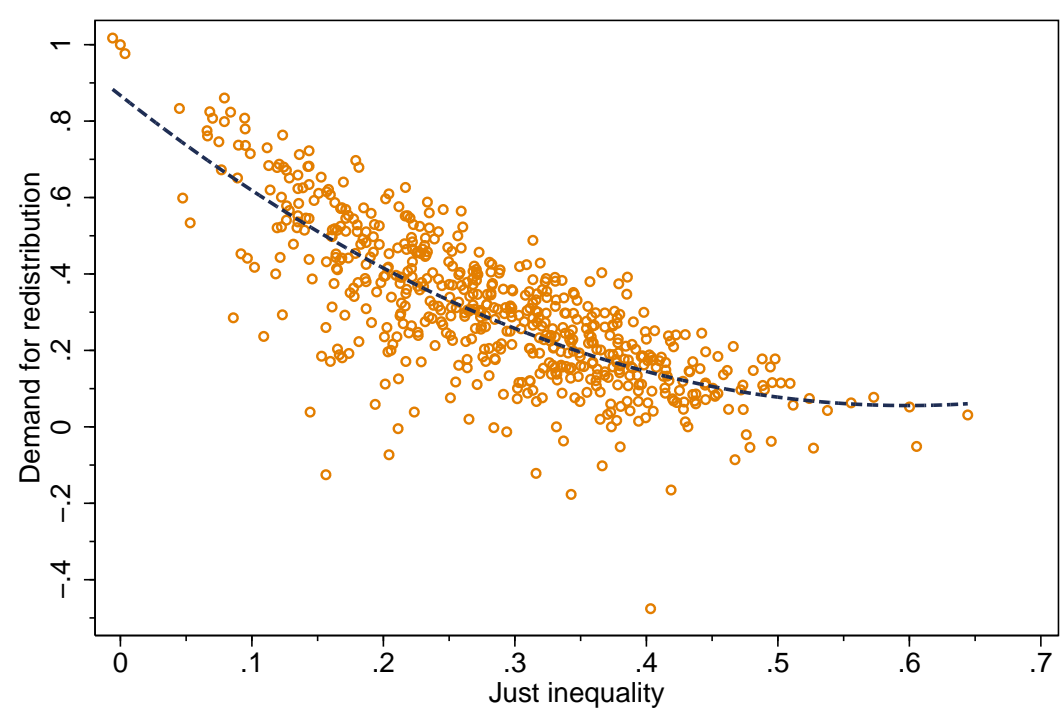

(b) Demand for redistribution versus ethical wage inequality

Notes: The figure at the top (at the bottom) shows the joint distribution of the demand for redistribution and the perceived (desired) wage inequality. The dashed lines are predicted values from a regression of the demand for redistribution on the actual inequality and it's square (top figure) and from a regression of the demand for redistribution on the desired inequality and it's square (bottom figure), respectively. 


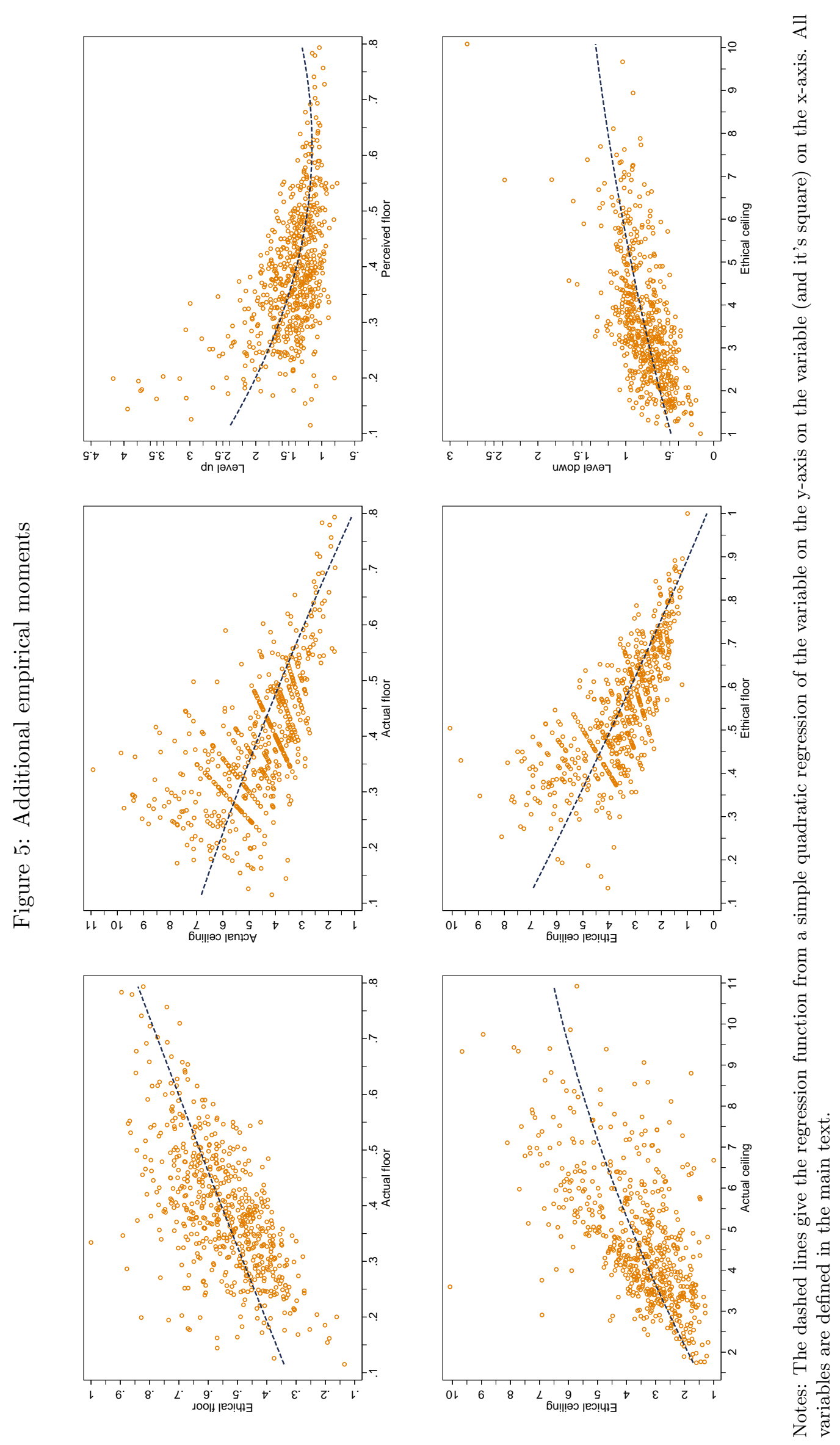



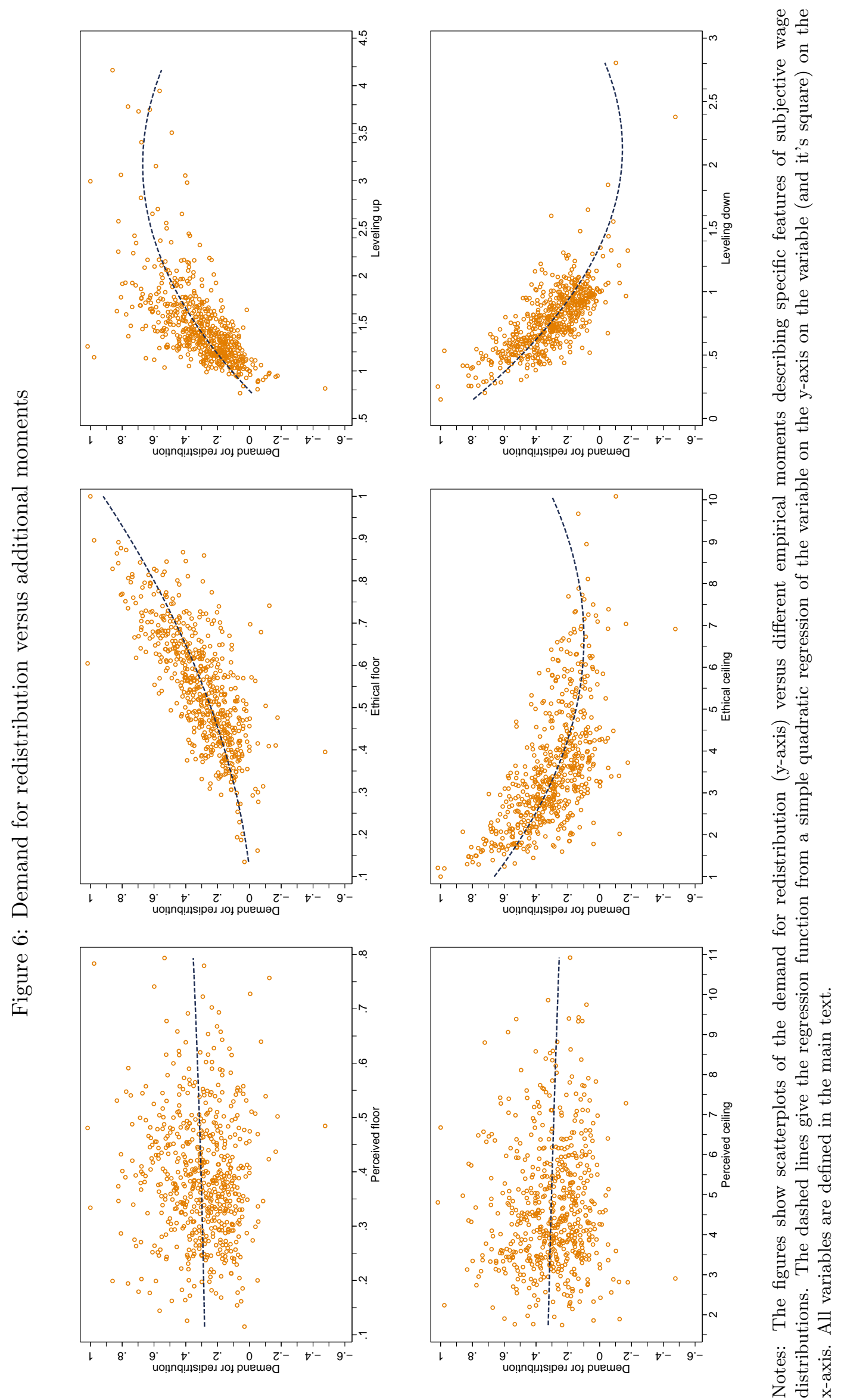


\section{A Variable Definitions}

\section{A.1 Dependent Variables}

Occupational Wage Estimates: Individuals were asked two questions about occupational wages (the wording is taken from the original source questionnaire of the ISSP):

1. "We would like to know what you think people in these jobs actually earn. Please write how much you think they actually earn each month (before taxes, but after social security contributions). Many people are not exactly sure about this, but your best guess will be close enough."

2. Next, what do you think people in these jobs ought to be paid. How much do you think they should earn each month (before taxes, but after social security contributions), regardless of what they actually earn."

Individuals were asked to estimate actual and just wages of people working in the following ten jobs (in the same order as in the survey):

1. "A skilled worker in a factory" (skilled worker)

2. "A doctor in general practice" (doctor)

3. "The chairman of a large national company" (chairman)

4. "A lawyer" (lawyer)

5. "A shop assistant in a big store" (shop assistant)

6. "The owner-manager of a large national factory" (owner factory)

7. "A judge at the Federal Supreme Court" (judge)

8. "An unskilled worker in a factory" (unskilled worker)

9. "A member of the Swiss Federal Council" (minister)

10. "Your own occupation" (coworker)

The phrasing in parentheses gives the label that is used in the text, the figures and the tables. All variables computed from these occupational wage estimates are discussed in more detail in section3.

Support for the welfare state: Individuals' support for the welfare state / for redistribution by the state is measured by a simple item from the survey:

1. "Do you agree or disagree? It is the responsibility of the government to reduce the differences in income between people with high incomes and those with low incomes."

The possible answers range from 1 ( "strongly disagree") to 5 ("strongly agree"). Alternatively, I also constructed a dichotomized variable which takes on the value one for values of either 4 or 5 on the original measure, and zero otherwise. 
Stated party preference: Individuals were asked whether they feel affiliated with one of the political parties in Switzerland (i.e. they were asked for which party they would vote if there were any elections at the time of the interview). The five relevant parties at the time of the interview were the following:

1. The liberal-democratic party ("Freisinnig-Demokratische Partei", FDP)

2. The christian-democratic party ("Christlichdemokratische Volkspartei", CVP)

3. The Swiss People's Party ("Schweizerische Volkspartei", SVP)

4. The social-democratic party ("Sozialdemokratische Partei der Schweiz", SPS)

5. The Greens Party of Switzerland ("Grüne Partei der Schweiz", GPS)

With respect to vote shares, these are the largest five parties in Switzerland. Members of the first four parties make up the Swiss Federal Council, the executive council at the national level.

\section{A.2 Independent Variables}

Income: Income is the personal net monthly income of individual $i$.

Justice evaluation: This variable corresponds to the ratio of just to actual wage estimate for individual $i$ 's coworkers, that is $\left(y(i)_{\text {coworker }}^{j} / y(i)_{\text {coworker }}^{a}\right)$, with $y(i)_{\text {coworker }}^{a}\left(y(i)_{\text {coworker }}^{j}\right)$ denoting individual $i$ 's estimate of his coworkers' actual (desired) wage.

Mobility: The only information about individuals' mobility is contained in two questions about their self-perception of the position today and the position ten years ago:

1. "In our society, there are groups which tend to be towards the top and groups which tend to be toward the bottom. Below is a scale that runs from top to bottom. Where would you put yourself on this scale?"

2. "And ten years ago, where did you fit then?"

Both are measured on a scale from 1 (bottom) to 10 (top). The mobility scale is simply defined as the difference between the two scores (position today minus position ten years ago).

Needs: This variable is meant to capture the extent to which an person thinks that one's needs should be important in determining their income (need principle). This variable is constructed as an univariate scale from the following two questions about which factors should be important in determining one's pay: "In deciding how much people ought to earn, how important should each of these things be, in your opinion?"

1. "What is needed to support your family."

2. "Whether the person has children to support." 
Effort: This variable is meant to capture the equity principle. This variable is constructed as an univariate scale from five questions about which factors should be important in determining pay: "In deciding how much people ought to earn, how important should each of these things be, in your opinion?"

1. "How much responsibility goes with the job."

2. "The number of years spent in education and training."

3. "Whether the job requires supervising others."

4. "How well he or she does the job."

5. "How hard he or she works at the job."

Ascribed skills: This variable measures the extent to which a person beliefs in ascribed factors as being important in determining the amount of compensation. This question relates to the perception of individuals of which factors actually are important for getting ahead. "We have some questions about opportunities for getting ahead":

1. "How important is coming from a wealthy family?"

2. "Knowing the right people?"

Acquired skills: This variable is the sum of over two different questions: "We have some questions about opportunities for getting ahead":

1. "Do you agree or disagree? In Switzerland, people get rewarded for their effort."

2. "In Switzerland, people get rewarded for their intelligence and skills."

Occupational prestige: This variable measures occupational prestige according to the Standard International Occupational Prestige Scale (SIOPS), see Ganzeboom and Treiman (1996).

Conflict: This variable measures individuals' perceptions of conflicts within society. Included items are questions about the existence of conflicts between: "In all countries, there are differences or even conflicts between different social groups. In your opinion, In Switzerland how much conflict is there between...:

1. "Poor people and rich people?"

2. "The working class and the middle class?"

3. "Management and workers?"

4. "People at the top of society and people at the bottom?"

5. "Young people and older people?"

Political scale: This variable measures individuals' self-rated position on a scale that takes on an integer value $j \in\{0, \ldots, 10\}$, with 0 (10) indicating the leftmost (rightmost) position. 


\section{B The Gini Coefficient with $k=2$}

For group-level wage data with $k$ different groups the Gini coefficient $G$ can be computed as follows: ${ }^{33}$

$$
\begin{aligned}
G & =\left(\left[\sum_{j=1}^{k} 0.5 \cdot\left(F_{j-1}+F_{j}\right) q_{j}\right]-0.5\right) / 0.5 \\
& =\left[\sum_{j=1}^{k}\left(F_{j-1}+F_{j}\right) q_{j}\right]-1,
\end{aligned}
$$

where $j=1, \ldots, k$ indexes the group, and the groups are ordered by their within-group average wage. $F_{j}$ denotes to the accumulated population share up to and including group $j$ and $q_{j}$ represents the wage share of group $j$. That is, $q_{j}=\left(f_{j} \cdot \bar{y}_{j}\right) / \sum_{j=1}^{k}\left(f_{j} \cdot \bar{y}_{j}\right)$, with $f_{j}$ denoting the population weight of group $j$ and $\bar{y}_{j}$ denoting the average wage of group $j$.

In the case of two groups only (i.e. $k=2$ ), the computation of $G$ simplifies considerably. Using the notation that $j=1=$ bottom and $j=2=$ top, writing equation (B.1) out yields:

$$
\begin{aligned}
G & =\left[\left(0+F_{\text {bottom }}\right) q_{\mathrm{bottom}}+\left(F_{\mathrm{bottom}}+F_{\mathrm{top}}\right) q_{\mathrm{top}}\right]-1 \\
& =\left[\left(0+f_{\mathrm{bottom}}\right) q_{\mathrm{bottom}}+\left(f_{\mathrm{bottom}}+1\right) q_{\mathrm{top}}\right]-1 \\
& =f_{\mathrm{bottom}} q_{\mathrm{bottom}}+f_{\mathrm{bottom}} q_{\mathrm{top}}+q_{\mathrm{top}}-1 \\
& =f_{\mathrm{bottom}}\left(q_{\mathrm{bottom}}+q_{\mathrm{top}}\right)+q_{\mathrm{top}}-1 \\
& =f_{\mathrm{bottom}}-q_{\mathrm{bottom}}
\end{aligned}
$$

The first equality of equation (B.2) follows from the fact that $F_{0}=0, F_{1}=F_{\text {bottom }}=f_{\text {bottom }}$, and $F_{2}=F_{\text {top }}=f_{\text {bottom }}+f_{\text {top }}=1$. The last equality follows from the fact that $\left(q_{\text {bottom }}+q_{\text {top }}\right)=1$ and therefore $\left(q_{\text {top }}-1\right)=-q_{\text {bottom }}$.

\footnotetext{
${ }^{33}$ This formula reflects the geometric interpretation of the Gini coefficient, being the ratio of the area between the curve representing equal distribution of wages and the Lorenz curve to the area under the curve representing equal distribution (which is equal to 0.5 by construction). In the case of grouped data, the area above the Lorenz curve can be computed as the sum over trapezoids:

$$
\sum_{j=1}^{k} 0.5 \cdot\left(F_{j-1}+F_{j}\right) q_{j}
$$

Subtracting 0.5 (which equals the area above the diagonal) and dividing by 0.5 (which also equals the area below the diagonal) therefore yields the Gini coefficient $G$.
} 


\section{Additional Sensitivity Checks}

\section{C.1 Sensitivity with Respect to Sample Selection}

One concern is whether the inequality measures and/or the regression results depend on the sample of observations which is actually available for the analysis. Table C.1 thus reports parameter estimates for the main model, estimated over different samples of observations. The first column replicates the main result (as given by table 4). Columns two and three show estimates for the same model, but each with an additional sample restriction. Column (2) adds the restriction that only individuals are included who gave estimates for actual and just wages for the same group of occupations. Column (3) restricts the sample to individuals who gave estimates for all (nine) occupations. Since there are considerable within-subject differences concerning the extent of occupational compensation, the subjective inequality measures might depend on the pattern of occupational wage estimates (that is, measures describing the actual and the desired wage distribution might differ, for the same individual, because the pattern of available wage estimates differs).

\section{Table C.1}

The remaining three columns are an attempt to increase the number of observations by a very simple method of missing data imputation. For each regressor, missing values were replaced by the mean value of the corresponding variable, and an indicator variable is created for each regressor, taking on the value 1 if the observation has missing information about that variable (and 0 otherwise). This way of dealing with missing data on covariates essentially maximizes the sample size without imputing missing values. Comparing columns one and four shows that this procedure increases the sample size by more than $50 \%$, without changing the qualitative pattern of estimates. The same holds true if I only consider observations with specific patterns of occupational wage estimates.

\section{C.2 Sensitivity With Respect to Population Weights}

Another potential problem of the measures proposed in this paper is that they involve an assumption about the proportion of 'poor' individuals in the population. To check the sensitivity of the main results with respect to the choice of the two population weights, table C.2 shows estimation results for different (reasonable) values of $f_{\text {bottom }}$ for the main empirical model.

\section{Table C.2}

The two rows at the top show that not only the mean, but also the variance of the redistribution measure monotonically increases with the population share of the bottom group $f$. More importantly, table C.2 shows that the qualitative pattern of the estimates does not depend on the value of $f$. This can in turn be attributed to the simple formulation of the subjective Gini coefficient: Changing $f_{\text {bottom }}$ does not change the ranking of the individuals as regards the Gini coefficient and thus cannot change the qualitative results from the regression models (i.e. the signs of the effects from the regressors) - as result that would not necessarily hold in the case of more than two groups. 


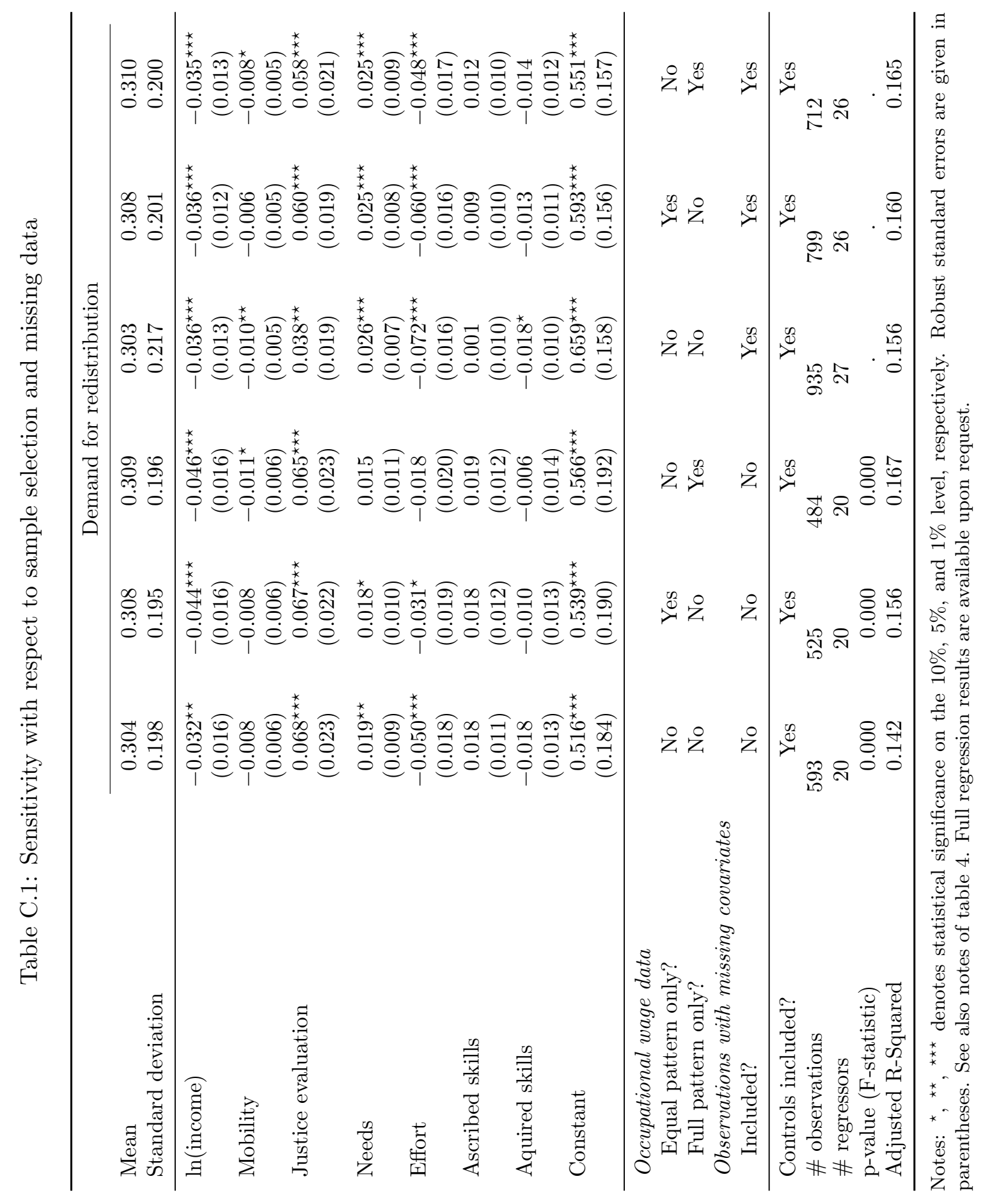




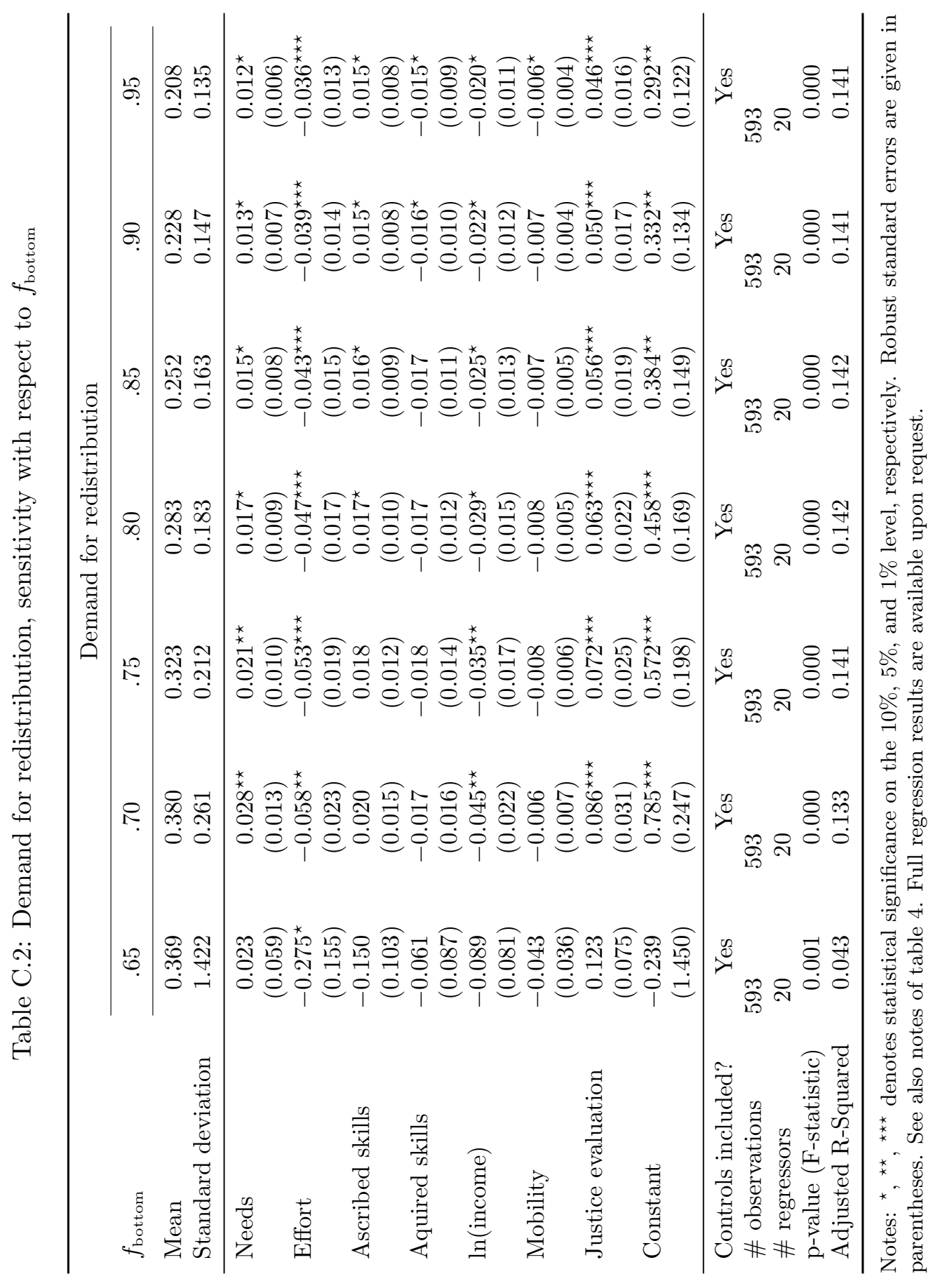




\section{Additional Tables and Figures}

Table D.1: Summary statistics

\begin{tabular}{lcc}
\hline & Analysis sample & Whole sample \\
\hline (a) Beliefs and perceptions & & \\
Needs & 3.247 & 3.341 \\
& $(1.011)$ & $(0.971)$ \\
Effort & 3.817 & 3.839 \\
& $(0.450)$ & $(0.454)$ \\
Ascribed skills & 3.026 & 2.986 \\
& $(0.758)$ & $(0.755)$ \\
Acquired skills & 3.311 & 3.307 \\
& $(0.609)$ & $(0.643)$ \\
(b) Self-interested motives & & \\
ln(income) & 8.336 & 8.194 \\
& $(0.663)$ & $(0.672)$ \\
Mobility & 0.543 & 0.415 \\
& $(1.620)$ & $(1.606)$ \\
Justice evaluation & 1.130 & 1.135 \\
& $(0.304)$ & $(0.276)$ \\
(c) Additional control variables & & \\
Occupational prestige & 46.626 & 44.521 \\
& $(12.335)$ & $(11.714)$ \\
Employed (yes = 1) & 0.841 & 0.673 \\
& $(0.366)$ & $(0.469)$ \\
Unemployed (yes = 1) & 0.022 & 0.030 \\
& $(0.147)$ & $(0.171)$ \\
Nonemployed (yes = 1) & 0.137 & 0.297 \\
& $(0.344)$ & $(0.457)$ \\
Age (years) & 43.411 & 45.151 \\
& $(13.532)$ & $(14.824)$ \\
Female (yes = 1) & 0.413 & 0.544 \\
Education (years) & $(0.493)$ & $(0.498)$ \\
Urban residence (yes = 1) & 13.413 & 12.855 \\
& $(2.638)$ & $(2.608)$ \\
Living in German-speaking part (yes $=1)$ & 0.653 & 0.659 \\
Foreign citizenship (yes $=1$ ) & $(0.477)$ & $(0.474)$ \\
Political self-assessement $(0.728$ & 0.712 \\
& 0.728 \\
Perception of conflicts & $(0.445)$ & $(0.453)$ \\
Number of observations & 0.148 & 0.156 \\
& $(0.356)$ & $(0.363)$ \\
& 4.789 & 4.856 \\
& $(1.686)$ & $(1.540)$ \\
& 2.337 & 2.380 \\
& $5.482)$ & $(0.521)$ \\
\hline
\end{tabular}

Notes: The first column shows means (standard deviations) for all control variables for the subsample used in the empirical analysis. The second column shows descriptives for the whole sample. 


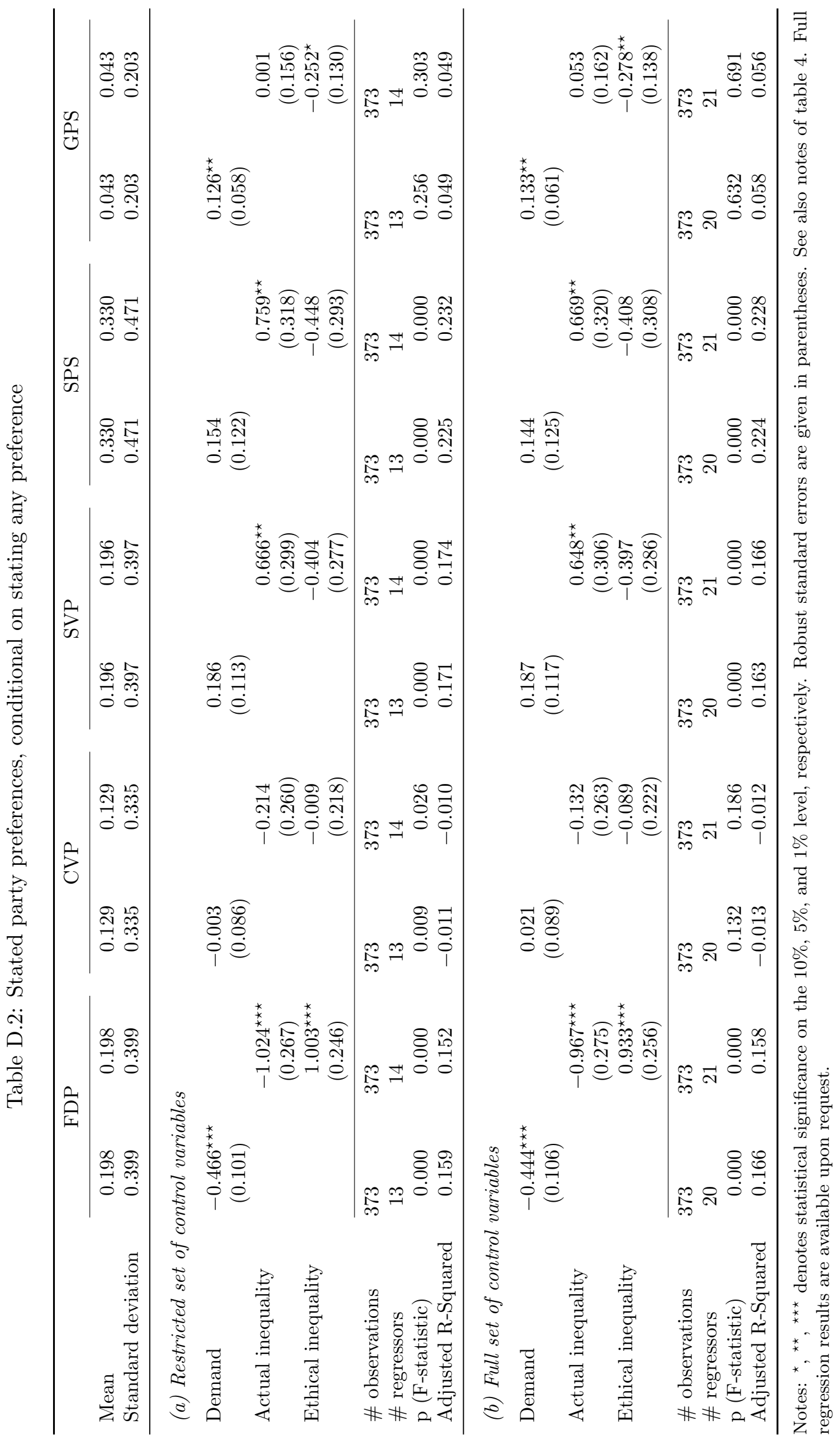




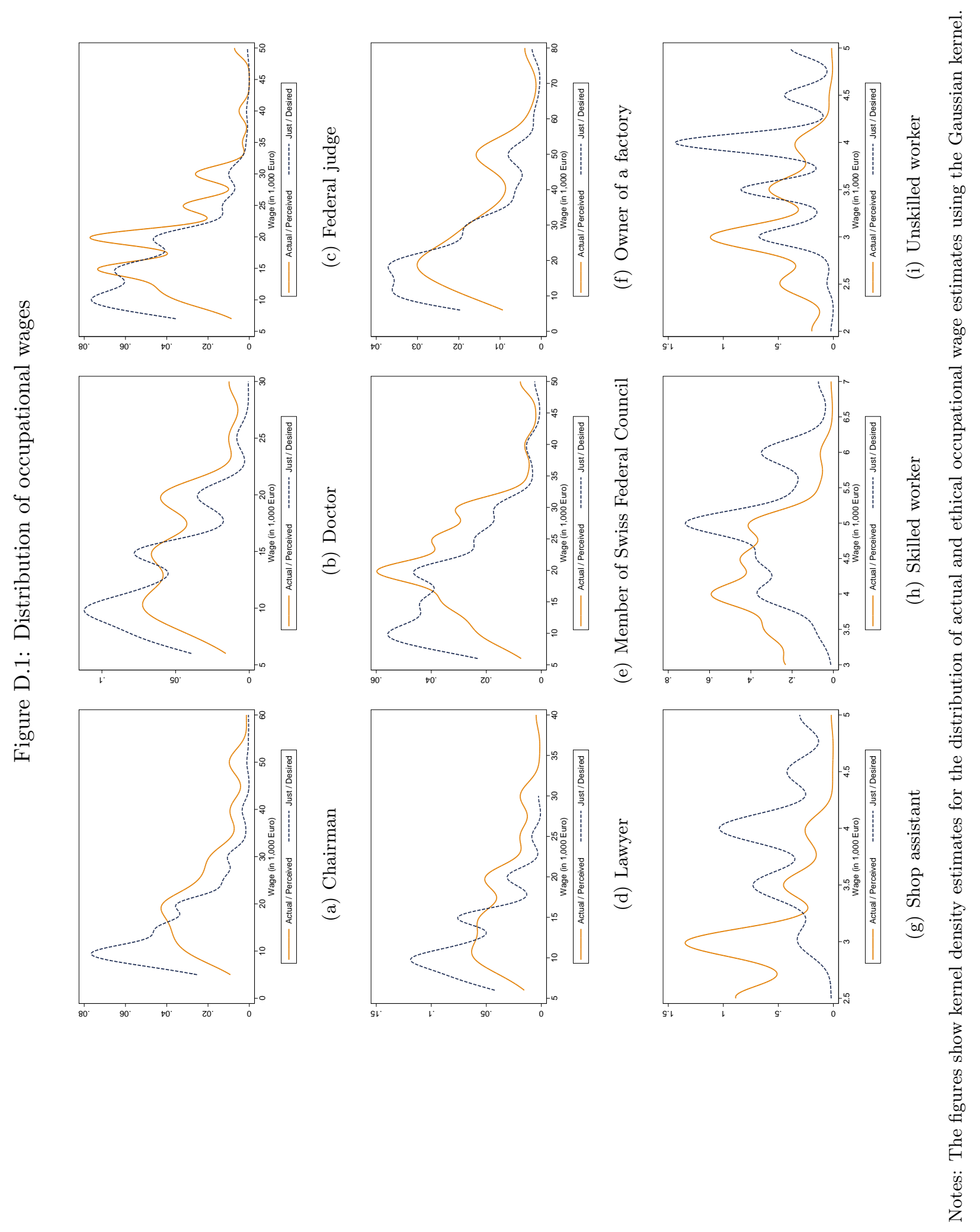

